This document is the accepted manuscript version of the following article:

Huang, T., Li, B., Yuan, Q., Shi, Z., Xie, Y., \& Shi, C. (2019). Rheological behavior of Portland clinker-calcium sulphoaluminate clinker-anhydrite ternary blend. Cement and concrete composites, 104, 103403 (14 pp.). https://doi.org/10.1016/j.cemconcomp.2019.103403

This manuscript version is made available under the CC-BY-NC-ND 4.0

license http://creativecommons.org/1icenses/by-nc-nd/4.0/

\title{
Rheological Behavior of Portland Clinker-Calcium Sulphoaluminate Clinker-Anhydrite Ternary Blend
}

Tingjie Huang, Ph.D student

School of Civil Engineering, National Engineering Laboratory for High Speed Railway Construction,

Central South University, Changsha 410075, China

Email: huangtj@csu.edu.cn, Tel: +8615608461125

Baiyuan Li, Master student

School of Civil Engineering, National Engineering Laboratory for High Speed Railway Construction,

Central South University, Changsha 410075, China

Email: Libaiyun@csu.edu.cn

*Qiang Yuan, Ph.D, Professor, Corresponding author

School of Civil Engineering, National Engineering Laboratory for High Speed Railway Construction,

Central South University, Changsha 410075, China

Email: Yuanqiang@csu.edu.cn, Tel:+86 13548955591

Zhenguo Shi, Ph. D,

Laboratory for Concrete \& Construction Chemistry, Swiss Federal Laboratories for Materials Science and Technology (Empa), 8600 Dübendorf, Switzerland

Email: zhenguo.shi@empa.ch

Youjun Xie, Ph.D, Professor

School of Civil Engineering, National Engineering Laboratory for High Speed Railway Construction,

Central South University, Changsha 410075, China

Email: xieyj@csu.edu.cn

Caijun Shi, Ph.D. Proferssor

Key Laboratory for Green \& Advanced Civil Engineering Materials and Application Technology of Hunan Province, College of Civil Engineering, HunanUniversity, Changsha, 410082, China

Email: cshi@hnu.edu.cn 


\section{$1 \quad$ Abstract}

2 In this paper, the rheological behavior of blended cements consisting of calcium sulphoaluminate

3 clinker (CSA), ordinary Portland clinker (OPC) and anhydrite $(C \bar{S})$ were investigated. The shear stress-

4 shear rate curves of OPC-CSA-C $\bar{S}$ blends with different OPC/CSA/C $\bar{S}$ ratios were analyzed. Several

5 rheological models were used to fit the rheological curves of cement pastes. The evolution of static

6 yield stress was also monitored to evaluate the structural build-up rate of the blends. Besides, zeta

7 potential measurement, calorimetric test, XRD and TGA analysis were carried out to reveal the

8 physico-chemical kinetics of the rheological evolution of fresh blends. It was found that not only CSH

9 gel but crystals of AFt and gypsum formed at the early age make contributions to the rheological

10 parameters, i.e. plastic viscosity, yield stress and structural build-up.

12 Keywords :

13 Ordinary Portland cement, Calcium sulfphoaluminate cement, Anhydrite, Physico-chemical kinetics, 14 Rheology

\section{Introduction}

17 Blends of ordinary Portland cement (OPC) and calcium sulfphoaluminate (CSA) cement are expected to combine advantages of these two cements and control specific properties of each, such as shrinkage

19 of OPC-based material, expansion of CSA-based material and their setting time [1-9].

21 Binary systems of OPC-CSA or ternary systems mixed with various calcium sulfates (dihydrate, hemihydrate and anhydrite) have been well investigated, including the mechanical properties, the 
microstructure $[10,11]$ and hydration process [12-14]. The ratio between the cements and the amount of calcium sulfate available in the system determines to a great extent the properties of composite systems. The setting time of OPC can be shortened by adding CSA, and the higher addition of CSA can considerably vary it $[14,15]$. Higher CSA cement content increased crystallization stress, which mass ratio, but decreased the strength at low OPC/CSA [10 12]. lead to more expansion-induced cracks, larger porosity, weaker tensile strength and smaller dynamic modulus [1]. The increase of CSA increased the compressive strength of blends at high OPC/CSA

A lot of researches indicated that the mixing of these two cements promoted early silicate and aluminate hydration $[12,13,18]$. They reacted very fast and AFt was formed within the first 5 min by the reaction between Ye'elimite (i.e., $\mathrm{C}_{4} \mathrm{~A}_{3} \overline{\mathrm{S}}$, the main component of the CSA clinker) and the calcium sulphates. Subsequently $\mathrm{C}_{2} \mathrm{~A} \overline{\mathrm{S}} \mathrm{H}_{8}$ and $\mathrm{CSH}$ were formed due to the reaction of $\mathrm{C}_{3} \mathrm{~S}$ at early period [13]. In case of OPC, the addition level of calcium sulphate should be optimized considering the content and reactivity of $\mathrm{C}_{3} \mathrm{~A}$, which leads to the formation of $\mathrm{AFt}$ at early age [17, 19]. However, calcium sulfate ion pairs are expected to adsorb onto tricalcium aluminate and reduce the overall reaction rate of OPC $[20,21]$. In case of CSA cement, calcium sulphate content controls the formation rate and the amount of AFt, affects the AFt/AFm ratio and the water demand to achieve complete hydration [22, 23]. For ternary blend, high calcium sulphate content increases AFt contents at early age, although it does not strongly influence the hydrate assemblage of the ternary binders at late period [13]. 
fresh stage is also of significance, it affects the construction quality of casting and forming process and also the properties of hardened concrete [24]. Particularly, in some advanced construction technologies, such as concrete 3D printing, smart casting and formless construction [25 27], the rheology of cementbased materials should make a balance between flowability before deposition and rate of structural build-up at rest [28]. CSA was applied to improve the shape holding capacity and enhance early strength of 3D printing OPC paste [29] and OPC-based self-levelling screed [30].

The chemical composition and physical characteristics of cement greatly influence its rheological properties. Mork et al. [31] noted that the yield stress and plastic viscosity of OPC paste increased with $\mathrm{SO}_{3}$ content. Dils et al. [32] pointed out that the OPC paste with high $\mathrm{C}_{3} \mathrm{~A}$ content, and lower $\mathrm{SO}_{3}$ content performed the worst rheological properties. García-Maté et al. [33] believed that the $\mathrm{SO}_{3}$ content did not present an important effect on the plastic viscosity of fresh CSA cement paste.

Recently, more and more attention has been focused on a time-dependent rheological parameter (i.e., the structural build-up rate) of cement-based material, which is due to the physical interactions between particles and the hydration of cement at early age $[34,35]$. The structural build-up is responsible for the increase of static yield stress and storage modulus of cement-based materials over time [36, 37]. A high build-up rate leads to a sufficient strength to sustain the weight of subsequent casting layers, as well as ensure strong bond between cast layers [38 40]. Furthermore, fast structural build-up rate can lead to high resistance of segregation and bleeding that can improve the quality of interface between aggregate and cement paste $[41,42]$. This directly affects the permeability, bond to steel and mechanical properties [43]. The structural build-up rate of ordinary Portland cement-based materials 
can be optimized by incorporating mineral admixtures [44 47], clays [48 52] and chemical additives [53].

Hydration kinetics plays an important role on structural build-up of cement-based material [34]. With the hydration of Portland cement particles going on, the precipitation of $\mathrm{CSH}$ gel on the surface of particles bridges the particles. It was considered as the main origin of structural build-up [35]. Therefore, the requirement of rheological properties of cement-based material leads to the new challenges of controlling the hydration at very early age. Hydration kinetics must be delayed to avoid setting during conveying and casting, but accelerated substantially after placing in the position in order to obtain the quick structuration $[27,28]$.

Although there are some studies on the rheological properties of Portland cement with CSA cement, the rheological properties of binary binder are affected by many factors, such as the type and content of calcium sulfate, the compositions of Portland cement and CSA cement. These are not well addressed in literature. By using three pure minerals, i.e. clinker of Portland cement, clinker of CSA and calcium sulfate, the rheological properties of binary binder of CSA and Portland can be studied in more details. The objective of the present study is to characterize the rheological behaviors of ternary blends composed of OPC clinker, CSA clinker and anhydrite. The influence of anhydrite dosage and of the OPC/CSA mass ratio on the instantaneous and time-dependent rheological parameters were studied. In order to provide more insightful evidence of rheology, zeta potential test was used to measure the electro-kinetic parameters, calorimetric test was conducted to evaluate the hydration reaction of cement paste, and X-ray diffraction and thermogravimetric analysis were employed to characterize the 
hydrates formed during rheological test period. Hopefully, this study can provide useful information

90 for designing a new binder with adopted rheological and setting behaviors.

91

92

\section{Experimental}

\subsection{Materials and sample preparation}

94 are shown in Fig. 1.

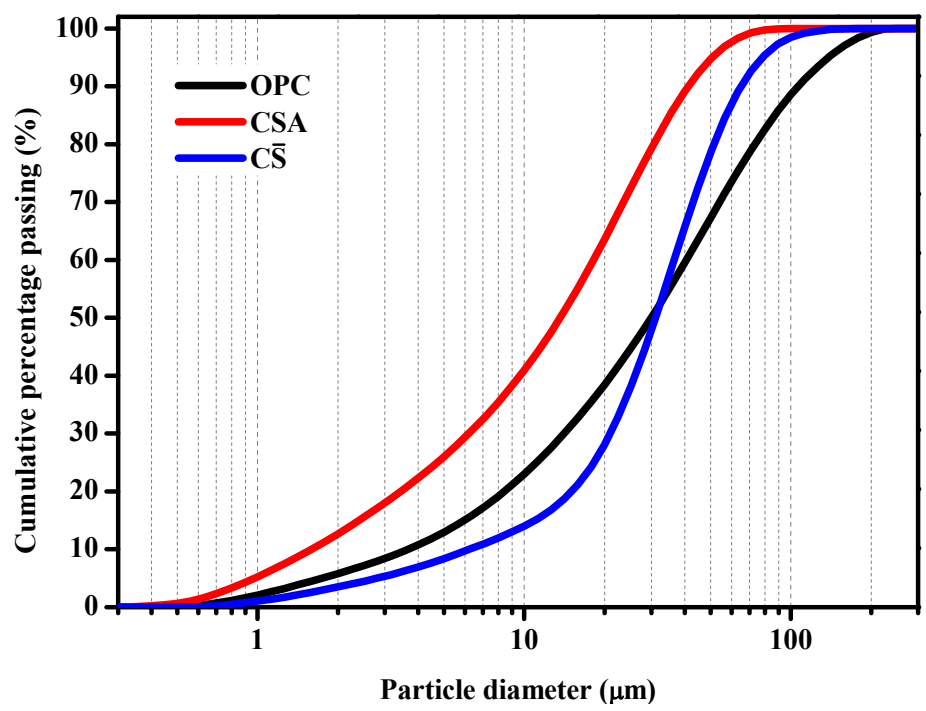

Fig. 1. Particle size distributions of powder materials

The mix proportions of the studied OPC-CSA-C $\bar{S}$ systems are given in Table 2 . The influence of the OPC/CSA mass ratio was investigated at certain $C \bar{S}$ content. Two $C \bar{S}$ contents $(5 \%$ and $10 \%)$ were employed to check the influence of the calcium sulphate content on the hydration mechanism and 
104 rheological behaviors of the composite cements. The water-to-powder (w/p) ratio of 0.5 was used to 105 prepare the paste samples. Water was first added into the Hobart N50 mixer, followed by adding the 106 powders. The mixture was first mixed at $60 \mathrm{rpm}$ for $60 \mathrm{~s}$, and then stopped and the paste sample was 107 manually homogenized for $30 \mathrm{~s}$, followed by mixing at $120 \mathrm{rpm}$ for $90 \mathrm{~s}$, and then at $60 \mathrm{rpm}$ for $30 \mathrm{~s}$.

108

109

\begin{tabular}{cccc}
\hline & OPC & CSA & $\mathrm{CS}$ \\
\hline $\mathrm{SiO}_{2}(\%)$ & 20.76 & 11.72 & 3.03 \\
$\mathrm{Al}_{2} \mathrm{O}_{3}(\%)$ & 4.58 & 22.83 & 0.59 \\
$\mathrm{Fe}_{2} \mathrm{O}_{3}(\%)$ & 3.27 & 1.50 & 0.29 \\
$\mathrm{CaO}(\%)$ & 62.13 & 46.79 & 39.53 \\
$\mathrm{MgO}(\%)$ & 3.13 & 1.72 & 0.68 \\
$\mathrm{SO}_{3}(\%)$ & 2.8 & 12.09 & 54.62 \\
Other minor oxides & 1.21 & 2.02 & 0.69 \\
Loss on ignition $(\%)$ & 2.12 & 1.33 & 0.57 \\
Density $\left(\mathrm{g} / \mathrm{cm}^{3}\right)$ & 3.14 & 2.81 & 2.97 \\
Blaine $\left(\mathrm{cm}^{2} / \mathrm{g}\right)$ & 2845 & 3770 & 3840 \\
\hline
\end{tabular}

110

\begin{tabular}{|c|c|c|c|c|c|c|c|c|c|c|c|}
\hline \multirow{2}{*}{ Sample } & \multicolumn{3}{|c|}{$\begin{array}{l}\text { Mass fraction } \\
\text { (wt.\%) }\end{array}$} & \multirow{2}{*}{$\begin{array}{c}\mathrm{OPC} / \mathrm{CS} \\
\text { A mass } \\
\text { ratio }\end{array}$} & \multirow{2}{*}{$\begin{array}{l}\text { Solid } \\
\text { volume } \\
\text { fraction } \\
(\%)\end{array}$} & \multirow{2}{*}{ Sample } & \multicolumn{3}{|c|}{$\begin{array}{l}\text { Mass fraction } \\
\text { (wt.\%) }\end{array}$} & \multirow{2}{*}{$\begin{array}{c}\mathrm{OPC} / \mathrm{CS} \\
\text { A mass } \\
\text { ratio }\end{array}$} & \multirow{2}{*}{$\begin{array}{c}\text { Solid } \\
\text { volume } \\
\text { fraction } \\
(\%)\end{array}$} \\
\hline & OPC & CSA & $C \bar{S}$ & & & & OPC & CSA & $\mathrm{C} \overline{\mathrm{S}}$ & & \\
\hline $5-10 / 0$ & 95 & 0 & 5 & $10 / 0^{*}$ & 38.98 & $10-10 / 0$ & 90 & 0 & 10 & $10 / 0^{*}$ & 39.05 \\
\hline $5-9 / 1$ & 85.5 & 9.5 & 5 & $9 / 1$ & 39.24 & $10-9 / 1$ & 81 & 9 & 10 & $9 / 1$ & 39.30 \\
\hline $5-8 / 8$ & 76 & 19 & 5 & $8 / 2$ & 39.50 & $10-8 / 8$ & 72 & 18 & 10 & $8 / 2$ & 39.54 \\
\hline $5-7 / 3$ & 66.5 & 28.5 & 5 & $7 / 3$ & 39.76 & $10-7 / 3$ & 63 & 27 & 10 & $7 / 3$ & 39.79 \\
\hline $5-6 / 4$ & 57 & 38 & 5 & $6 / 4$ & 40.02 & $10-6 / 4$ & 54 & 36 & 10 & $6 / 4$ & 40.03 \\
\hline $5-5 / 5$ & 47.5 & 47.5 & 5 & $5 / 5$ & 40.27 & $10-5 / 5$ & 45 & 45 & 10 & $5 / 5$ & 40.27 \\
\hline $5-4 / 6$ & 38 & 57 & 5 & $4 / 6$ & 40.53 & $10-4 / 6$ & 36 & 54 & 10 & $4 / 6$ & 40.51 \\
\hline $5-3 / 7$ & 28.5 & 66.5 & 5 & $3 / 7$ & 40.78 & $10-3 / 7$ & 27 & 63 & 10 & $3 / 7$ & 40.75 \\
\hline $5-2 / 8$ & 19 & 76 & 5 & $2 / 8$ & 41.02 & $10-2 / 8$ & 18 & 72 & 10 & $2 / 8$ & 40.98 \\
\hline $5-1 / 9$ & 9.5 & 85.5 & 5 & $1 / 9$ & 41.27 & $10-1 / 9$ & 9 & 81 & 10 & $1 / 9$ & 41.22 \\
\hline $5-0 / 10$ & 0 & 95 & 5 & $0 / 10^{*}$ & 41.51 & $10-0 / 10$ & 0 & 90 & 10 & $0 / 10^{*}$ & 41.45 \\
\hline
\end{tabular}

112 Note: *: Binary blend, OPC $+\mathrm{C} \overline{\mathrm{S}}$ blend or $\mathrm{CSA}+\mathrm{C} \overline{\mathrm{S}}$ blend, 5-9/1 denotes $5 \% \mathrm{C} \overline{\mathrm{S}}$ in the powder with $90 \% \mathrm{OPC}$ and $113 \quad 10 \%$. 


\subsection{Rheological test}

116 Anton paar Rheolab QC rheometer was used for rheological test. The type of rotator was CC39 with a 117 diameter of $4.000 \mathrm{~cm}$, and the inner diameter of the cylinder was $4.194 \mathrm{~cm}$. In order to minimize the 118 slip, the surfaces of the container and rotator which are in contact with cement paste were sandblasted. 119 After mixing, the paste was immediately poured into the cylinder. Two batches of mixtures were 120 prepared for both dynamic test and static test.

\subsubsection{Dynamic test}

Dynamic yield stress test was started at $5 \mathrm{~min}$ after the contact of cement and water, and the test was conducted as follows: pre-shear the paste at $100 \mathrm{~s}^{-1}$ for $60 \mathrm{~s}$, then stop for $15 \mathrm{~s}$, followed by linearly 125 increasing shear rate from 0 to $100 \mathrm{~s}^{-1}$ within $60 \mathrm{~s}$.

In order to choose the best model to characterize the dynamic rheological behavior of the different blends, four common models (Eq. 1 4) were used to fit descending curve of shear rate from $20 \mathrm{~s}^{-1}$ to $129100 \mathrm{~s}^{-1}$ respectively and calculate rheological parameters.

130 Bingham (B) model:

$$
\tau=\tau_{0}+\mu \dot{\gamma}
$$

132 Modified Bingham (MB) model:

$$
\tau=\tau_{0}+\mu \dot{\gamma}+c \dot{\gamma}^{2}
$$

134 Herschl-Bulkley (H-B) model:

$$
\tau=\tau_{0}+K \dot{\gamma}^{n}
$$

136 Casson (C) model: 


$$
\tau=\tau_{0}+\eta_{\infty} \dot{\gamma}+2\left(\tau_{0} \eta_{\infty}\right)^{1 / 2} \dot{\gamma}^{1 / 2}
$$

138 where $\tau_{0}$ is dynamic yield stress, $\mu$ is apparent viscosity, $\mathrm{c}$ is the second order parameter in $\mathrm{Pa} \cdot \mathrm{s}^{2}, \mathrm{~K}$

139 is consistency index, $\mathrm{n}$ is non-Newton index and $\eta_{\infty}$ is infinite viscosity.

\subsubsection{Static test}

142 For static test, a thin layer of oil was dropped on the surface of the sample to prevent the evaporation 143 of water after pouring the sample into cylinder. The paste was at rest until specific testing time (10 45 $144 \mathrm{~min}$ ), static yield stress test was performed by constant shearing paste at $0.005 \mathrm{~s}^{-1}$ for $60 \mathrm{~s}$ to reach steady state [37]. The peak value of shear stress measured during this period was recorded as the static yield stress. For each resting time a new sample was employed. Since the capacity of shearing force of the equipment was $450 \mathrm{~Pa}$, some samples reached the limit before $45 \mathrm{~min}$, and the test was stopped. During the entire test, the temperature of the sample was maintained at $25{ }^{\circ} \mathrm{C}$ by water bath.

In this study, the model (see in Eq. 5) proposed by Perrot et al. [54] was employed to fit the data of static yield stress $\tau_{\mathrm{s}}$. The parameter $\mathrm{A}_{\text {thix }}$ was introduced to characterize the structural build-up rate of plain and composite cement paste. The higher $\mathrm{A}_{\text {thix }}$ reflects faster structural build-up of cement paste [76].

$$
\tau_{0}(t)=\tau_{0,0}+A_{\text {thix }} t_{c}\left(e^{\frac{t_{\text {rest }}}{t_{c}}}-1\right)
$$

where $t_{c}$ is a characteristic time, the value of which is adjusted to obtain the best fit with experimental 156 values. 
The zeta potential was measured using the "ZetaProbe" equipment based on the electroacoustic technique. A diluted blend was made for zeta potential measurement. The $\mathrm{w} / \mathrm{p}$ ratio was 5 . The mix proportion of samples were the same to those in rheological test, as shown in Table 2. OPC, CSA, C $\bar{S}$ and distilled water were mixed in a mixer for $2 \mathrm{~min}$ at $300 \mathrm{rpm}$. About $300 \mathrm{ml}$ of the paste was poured in the sample cell of ZetaProbe. During the test, the samples were kept stirring at a speed of $300 \mathrm{rpm}$ so that a uniform cement suspension passes through the electrodes of the cell. The zeta potential, $\mathrm{pH}$ value and the conductivity of the cement solution were measured every 20 s and Debye length was calculated automatically by the apparatus [55].

\subsection{Calorimetric test}

\subsubsection{Test procedure}

TAM Air thermal activity micro-calorimeter was used to measure the hydration heat of the blended cements. The twin-chamber testing channel is the typical characteristics of this apparatus, and one contains the distilled water and the other contains the predetermined amount of paste. The mixing program was the same as rheological test. After mixing, the paste was immediately transferred into the apparatus. During the test, the ambient temperature around the samples were maintained at $25{ }^{\circ} \mathrm{C}$. The test started at 6 min after mixing the blended cements with water. The data were recorded every $10 \mathrm{~s}$.

\subsubsection{Calculation of hydration kinetic parameters}

The boundary nucleation and growth (BNG) model [56] has shown some advantages to describe the hydration kinetics of Portland cement [57] and calcium sulphoaluminate cement [58]. In this model, the rates of nucleation and growth are assumed to be constant throughout the whole hydration process, 
and the nucleation of hydrates occurs randomly on the surface of cement particles.

According to BNG model, the volume fraction of hydrates $(\mathrm{X}(\mathrm{t}))$ at a given time was used to estimate

the degree of hydration $\alpha(t)$, which can be expressed as Eq. 6 [57 62].

$$
\begin{gathered}
\alpha(t)=\mathrm{X}(\mathrm{t})=1-\exp \left\{-\mathrm{S} \int_{0}^{\mathrm{Gt}}\left[1-\exp \left(\frac{-\pi N}{3} \mathrm{G}^{2} \mathrm{t}^{3}\left(1-\frac{3 \mathrm{y}^{2}}{\mathrm{G}^{2} \mathrm{t}^{2}}+\frac{2 \mathrm{y}^{3}}{\mathrm{G}^{3} \mathrm{t}^{3}}\right)\right] \mathrm{dy}\right\}\right. \\
\mathrm{S}=\frac{\text { Blaine specific surface area of particles }}{\text { density of particles }}
\end{gathered}
$$

where $S$ is the value of surface area for the solid particles per unit volume $\left(\mu \mathrm{m}^{-1}\right)$ and calculated by Eq.

$7, \mathrm{G}$ is the growth rate of nuclei $(\mu \mathrm{m} / \mathrm{h}), \mathrm{N}$ is the formation rate of nuclei $\left(\mu \mathrm{m}^{-2} \mathrm{~h}^{-1}\right)$ and $\mathrm{y}$ is a dummy

variable. The degree of hydration $\alpha(\mathrm{t})$ is estimated by calorimetric test using Eq. 8 .

$$
\alpha(t)=\frac{Q(t)}{Q_{\max }}
$$

$\mathrm{Q}_{\max }$ is the total heat released from the hydration of cementitious materials as measured by calorimetric

The formation rate of nuclei $(\mathrm{N})$ and its growth rate $(\mathrm{G})$ are both dominant parameters controlling the early hydration. Because the nuclei growth is anisotropic, the rate of tangent direction was defined as

gG. Additionally, a parameter $\mathrm{p}$ was proposed to describe the proportion of growth rate inside and outside grain [56]. By further defining $\mu=y /(G t)$, Eq. 6 can be written as Eq. 9:

$$
X(t)=1-\exp \left\{-2 p S G t \int_{0}^{1}\left[1-\exp \left(\frac{-\pi N}{3} g^{2} t^{3}(1-\mu)^{2}(1+2 \mu)\right] d \mu\right\}, \mu<1\right.
$$

Two independent rate constants $\mathrm{k}_{\mathrm{N}}$ and $\mathrm{k}_{\mathrm{G}}$ were proposed to describe the kinetics of a boundarynucleated process (Eq. 10 and 11). 


$$
\begin{gathered}
k_{N}=\pi g G^{2} N / 3 \\
k_{G}=p S G
\end{gathered}
$$

According to refs. [56, 57], $1 / \mathrm{k}_{\mathrm{G}}$ was defined as the time for hydration products reaching the radius of

"reaction vessel". $1 /\left(\mathrm{K}_{\mathrm{N}}\right)^{1 / 3}$ was the time needed for part of hydration products along the boundary of cement particles to become unity. Thus, the $\mathrm{X}(\mathrm{t})$ can be expressed as follows (Eq. 12).

$$
X(t)=1-\exp \left\{-2 \mathrm{k}_{G} t \int_{0}^{1}\left[1-\exp \left(-k_{N} t^{3}(1-\mu)^{2}(1+2 \mu)\right] d \mu\right\}, \mu<1\right.
$$

According to the literature [57], the BNG model fits well the calorimetric data, and the heat flow can be defined as $\mathrm{A}(\mathrm{dx} / \mathrm{dt})$, where $\mathrm{A}$ is the scaling parameter. The measured heat flow data, in particular the data between the minimum in the induction period and the second peak, were used to determine $\mathrm{K}_{\mathrm{N}}$ and $\mathrm{K}_{\mathrm{G}}$ values

\subsection{Solid phase Analysis}

\subsubsection{X-ray diffraction analysis}

After mixing of the blended materials, the fresh paste was placed on a glass microscope slide and set at X-ray diffractometer at $25^{\circ} \mathrm{C}$. The XRD measurements started at $15 \mathrm{~min}$ and $30 \mathrm{~min}$ after the contact of cement and water. X-ray diffraction analyses was carried out at $25{ }^{\circ} \mathrm{C}$ with a Bruker D8 Advance diffractometer $(\mathrm{Cu} \mathrm{K \alpha}$ radiation, $45 \mathrm{~mA}, 35 \mathrm{kV})$ with a Super speed detector, in the $2 \theta$ range $5 \sim 35^{\circ}$, with a scanning step size of $6^{\circ} 2 \theta / \mathrm{min}$ (total measurement time of $5 \mathrm{~min}$ ). The crystalline phases were analyzed using the EVA software. 


\subsubsection{Thermogravimetric analysis}

217 The hydration of the blend was stopped before thermogravimetric analysis (TGA). 5 grams of the sample after hydration of 10, 20, 30 and $45 \mathrm{~min}$ was ground with $100 \mathrm{ml}$ of acetone to fine powder in

219 an agate mortar prior to stopping hydration. The ground samples were filtrated with a Whatman filter

220 (90 mm diameter with a pore size of $2.5 \mu \mathrm{m})$ and a Teflon support. The samples were washed twice 221 with acetone and finally washed with diethyl ether [63]. The resulting samples were stored in a 222 desiccator to avoid further hydration and any possible carbonation.

TGA was carried out with a TGA 2(SF)-Mettler Toledo. Approximately $50 \mathrm{mg}$ of the prepared powdered samples were tested from $35{ }^{\circ} \mathrm{C}$ to $950{ }^{\circ} \mathrm{C}$ at a heating rate of $10{ }^{\circ} \mathrm{C} / \mathrm{min}$ under a $\mathrm{N}_{2}$ atmosphere.

\section{Results}

\subsection{Dynamic rheology}

\subsubsection{Rheological models of OPC-CSA-C $\bar{S}$ blend}

The typical shear stress vs. shear rate flow curves of OPC-CSA-C $\bar{S}$ blends are plotted in Fig. 2. The paste shows shear thinning behavior in the measured shear rate region regardless of OPC/CSA mass ratio and $C \bar{S}$ content. In order to evaluate whether the mathematic equations are suitable for the measured data, standard deviation (SD) calculated by Eq. 12 was adopted to compare the compliance of various rheological models and shear stress-shear rate data. In Eq. 12, $\mathrm{y}_{\text {mea }}$ is measured shear stress, $\mathrm{y}_{\text {pre }}$ is the predicted value by the rheological models. The results are shown in Table 3.

$$
\mathrm{SD}=\sqrt{\frac{\sum_{i=1}^{n}\left(y_{\text {mea }}-y_{\text {pre }}\right)^{2}}{n-1}}
$$


239 As seen in Table 3, the Herschel-Bulkley (H-B) and modified Bingham (MB) models have lower SD

240 values than Bingham (B) and Casson (C) models, particularly in case of lower OPC/CSA ratio and

241 higher $\mathrm{C} \bar{S}$ content. However, the H-B model has higher SD values for ternary blends with higher

242 OPC/CSA ratio and binary CSA-C $\bar{S}$ blends than that of MB model. This means that the modified

243 Bingham model has the best fitting for shear stress-shear rare data of OPC-CSA-C $\bar{S}$ blends.

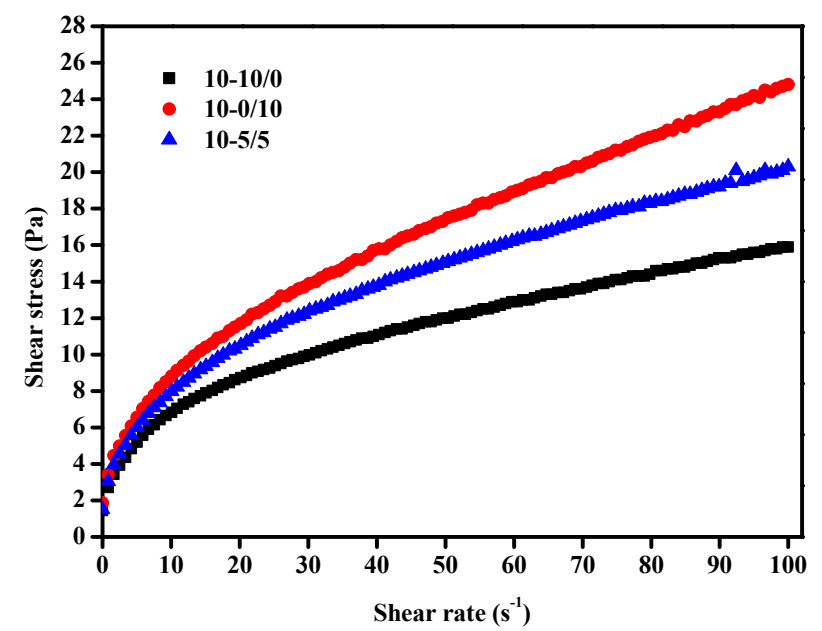

Fig. 2 Typical rheological curves of blends

Table 3 Standard deviation (SD) values for the models investigated

\begin{tabular}{ccccccccc}
\hline \multirow{2}{*}{$\begin{array}{c}\text { OPC/CSA } \\
\text { ratio }\end{array}$} & \multicolumn{4}{c}{$5 \% \mathrm{C} \overline{\mathrm{S}}$} & \multicolumn{5}{c}{$10 \% \mathrm{C} \overline{\mathrm{S}}$} \\
\cline { 2 - 9 } & $\mathrm{B}$ & $\mathrm{MB}$ & $\mathrm{H}-\mathrm{B}$ & $\mathrm{C}$ & $\mathrm{B}$ & $\mathrm{MB}$ & $\mathrm{H}-\mathrm{B}$ & $\mathrm{C}$ \\
\hline $10 / 0$ & 0.1098 & 0.1375 & 0.0754 & 0.350 & 0.0901 & 0.090 & 0.1133 & 0.442 \\
$9 / 1$ & 0.1807 & 0.0408 & 0.3135 & 0.461 & 0.1831 & 0.0979 & 0.0803 & 0.482 \\
$8 / 2$ & 0.1174 & 0.0769 & 0.1671 & 0.339 & 0.2108 & 0.0822 & 0.0775 & 0.378 \\
$7 / 3$ & 0.1929 & 0.1426 & 0.1441 & 0.515 & 0.1879 & 0.1528 & 0.0775 & 0.535 \\
$6 / 4$ & 0.2285 & 0.0631 & 0.1132 & 0.572 & 0.2051 & 0.0785 & 0.1020 & 0.657 \\
$5 / 5$ & 0.2157 & 0.1672 & 0.1151 & 0.494 & 0.2204 & 0.1663 & 0.0842 & 0.810 \\
$4 / 6$ & 0.3098 & 0.1047 & 0.0986 & 0.542 & 0.2332 & 0.0936 & 0.0655 & 0.481 \\
$3 / 7$ & 0.3606 & 0.1182 & 0.0787 & 0.418 & 0.2486 & 0.1100 & 0.0754 & 0.531 \\
$2 / 8$ & 0.4795 & 0.1267 & 0.0938 & 0.688 & 0.2955 & 0.1318 & 0.0842 & 1.003 \\
$1 / 9$ & 0.6140 & 0.1375 & 0.0931 & 0.763 & 0.3690 & 0.1019 & 0.0775 & 1.381 \\
$0 / 10$ & 0.5230 & 0.0998 & 0.2699 & 0.378 & 0.1776 & 0.0696 & 0.0752 & 0.498 \\
\hline
\end{tabular}




\subsubsection{Yield stress and plastic viscosity}

248 Yield stress and plastic viscosity are two parameters, which should be fitted to quantitatively assess 249 the rheological behavior of the blends. Fig. 3 presents the yield stress obtained by four models. The H-

250 B model predicts the lowest yield stress, which is one order of magnitude lower than the yield stress 251 predicted by other rheological models. Nevertheless, the results calculated by different models shows 252 a similar trend. It reveals that the dynamic yield stress of blend depends not only on OPC/CSA ratio, 253 but also relates to $\mathrm{C} \bar{S}$. Independent of the types of models used, for a given $\mathrm{C} \overline{\mathrm{S}}$ content, the dynamic 254 yield stress $\left(\tau_{0}\right)$ of ternary composite cement paste is higher than binary $\mathrm{OPC}+\mathrm{C} \overline{\mathrm{S}}$ paste. The models predict that the $\tau_{0}$ value of ternary blends is even higher than that of CSA $+\mathrm{C} \bar{S}$ paste. Additionally, the $\tau_{0}$ value is smaller at higher OPC/CSA ratio, while the dynamic yield stresses of those with $10 \% \mathrm{CS}$ are lower than those with $5 \% \mathrm{C} \bar{S}$ at the same OPC/CSA ratio.
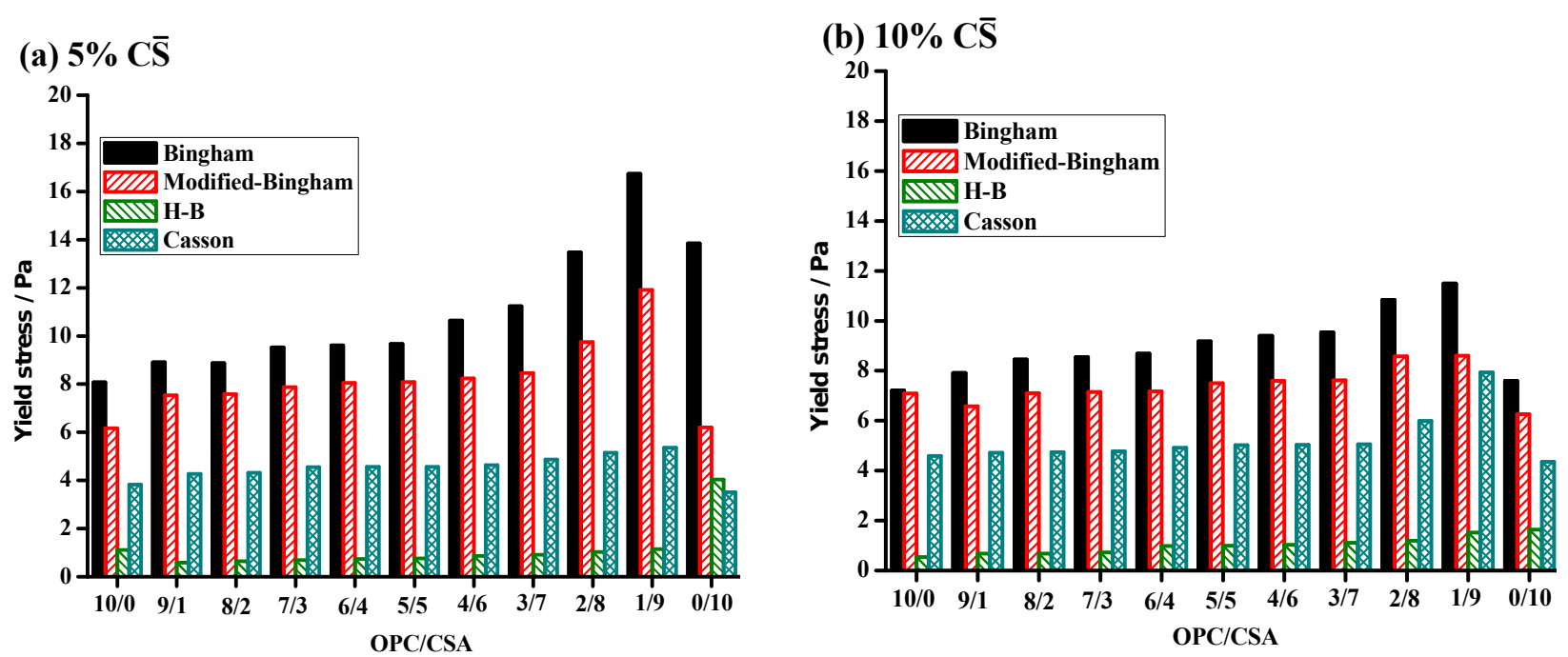

Fig. 3. The dynamic yield stress of pastes obtained by various models.

Fig. 4 shows the plastic viscosity and consistency index predicted by Bingham model and MB model. 
ratio, however, the Bingham model shows higher values at lower OPC/CSA ratio. For ternary blends, the influence of $\mathrm{OPC} / \mathrm{CSA} / \mathrm{C} \bar{S}$ mass ratio on the plastic viscosity/consistency index calculated by these two models are similar. The plastic viscosity/consistency index increases both with CSA content and $\mathrm{C} \overline{\mathrm{S}}$ content. Most of the plastic viscosities of ternary blends are larger than that of binary OPC + $\mathrm{C} \bar{S}$ and $\mathrm{CSA}+\mathrm{C} \overline{\mathrm{S}}$ pastes.

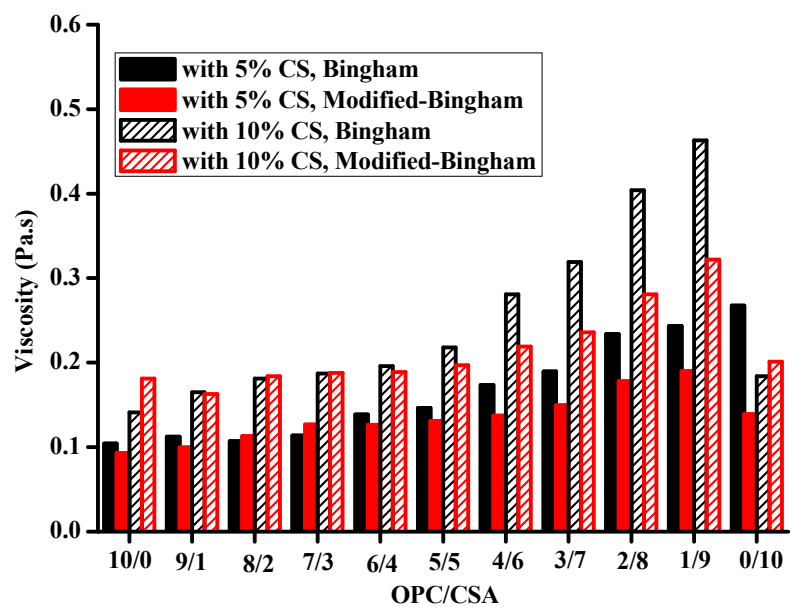

Fig. 4. The apparent viscosity of samples obtained by Bingham and Modified-Bingham

\subsubsection{Shear-thinning intensity}

269 In order to evaluate the shear-thinning intensity of the blends, the non-Newton index n was calculated based on the H-B model as summarized in Table 4. It can be observed that all of the $\mathrm{n}$ values of blends are less than 1, which means that all of them exhibit shear-thinning behavior [64]. The lower $n$ value indicates a higher intensity of shear-thinning when $n<1[64]$. The results show that with the addition of $\mathrm{C} \bar{S}$ the shear-thinning intensity is increased for the OPC paste, but decreased for the CSA paste. The result also shows that the shear-thinning intensity of ternary OPC-CSA-C $\bar{S}$ blend is enhanced with 275 increasing the $\mathrm{C} \bar{S}$ content. However, the highest shear-thinning intensity is obtained for the blends when the OPC content is close to CSA content (in this study, the highest shearing-thinning intensity is observed at $\mathrm{OPC} / \mathrm{CSA}=6 / 4$ or $5 / 5$, when the content of $\mathrm{CS}$ is $5 \%$ or $10 \%$ ). 
279 In summary, the initial rheological parameter of cement pastes with ternary OPC-CSA-C $\bar{S}$ system 280 depends not only on OPC/CSA ratio, but also on the content of C $\bar{S}$. The decrease of the OPC/CSA 281 ratio leads to a higher yield stress and a higher plastic viscosity. However, increasing the percentage 282 of $\mathrm{C} \bar{S}$ in ternary system results in a lower dynamic yield stress but a higher plastic viscosity and a 283 higher shear-thinning intensity.

Table 4 The non-Newton index of sample obtained by H-B model

\begin{tabular}{ccc}
\hline OPC/CSA ratio & $5 \% \mathrm{C} \overline{\mathrm{S}}$ & $10 \% \mathrm{C} \overline{\mathrm{S}}$ \\
\hline $10 / 0$ & 0.420 & 0.450 \\
$9 / 1$ & 0.440 & 0.449 \\
$8 / 2$ & 0.420 & 0.445 \\
$7 / 3$ & 0.411 & 0.429 \\
$6 / 4$ & 0.389 & 0.435 \\
$5 / 5$ & 0.389 & 0.410 \\
$4 / 6$ & 0.387 & 0.442 \\
$3 / 7$ & 0.390 & 0.420 \\
$2 / 8$ & 0.402 & 0.505 \\
$1 / 9$ & 0.440 & 0.601 \\
$0 / 10$ & 0.736 & 0.427 \\
\hline
\end{tabular}

\subsection{Electro-kinetic characteristics}

287 Table 5 shows the average values of electro-kinetic parameters (zeta potential, Debye length, 288 conductivity and $\mathrm{pH}$ value) of $\mathrm{C} \overline{\mathrm{S}}$ solution, OPC solution, $\mathrm{CSA}$ solution, $\mathrm{OPC}+\mathrm{C} \overline{\mathrm{S}}$ diluted blends 289 and CSA $+C \bar{S}$ diluted blends over $20 \mathrm{~min}$. The change in zeta potential depends on either a change 290 in surface charge or adsorption of ions to the surfaces. Debye length reflects the scope where repulsive 291 electrostatic effect persists. Debye length relates on the ionic strength of the bulk electrolyte. The 292 conductivity of cement solution reflects the ionic concentration and ionic conductivity. [65] 
294 It can be seen that the zeta potentials $(\zeta)$ of the suspensions of $\bar{C}$, OPC, CSA are all positive, the value 295 of OPC solution is the largest while that of CSA solution is the smallest and close to zero. Although $2965 \% \mathrm{C} \bar{S}$ content shortens the Debye length of OPC solution and CSA solution while $10 \% \mathrm{C} \bar{S}$ content 297 enlarges the value of Debye length, the influence of $\bar{C} \bar{S}$ in zeta potential values of OPC solution and 298 CSA solution differs. In case of OPC $+\mathrm{C} \bar{S}$ binary blend, the increase in $\mathrm{C} \overline{\mathrm{S}}$ content decreases the zeta potential. Conversely, in case of $\mathrm{CSA}+\mathrm{C} \overline{\mathrm{S}}$ blend, larger proportion of $\mathrm{C} \overline{\mathrm{S}}$ leads to higher $\zeta$ value.

The average electro-kinetic parameters of OPC-CSA-C $\bar{S}$ blends are also listed in Table 6 . The result notes that except for sample 5-3/7, the zeta potentials of ternary blends are positive, the increase of CSA content reduces $\zeta$ value of blends. For blends with $5 \% \mathrm{C} \bar{S}$, increasing CSA content decreases the conductivity and $\mathrm{pH}$ value. The lower conductivity and $\mathrm{pH}$ value reflect the less dissolved ions stemming from blend. It may contribute to lower value of ionic strength. Thus, Debye length increases.

306 For blends with $10 \% \mathrm{C} \overline{\mathrm{S}}$, the conductivity and $\mathrm{pH}$ value decrease with the CSA content when OPC/CSA is larger than 4/6, but it turns to increase with CSA content at the lowers. The Debye length of blends with $10 \% \mathrm{C} \bar{S}$ thus shows an opposite trend. Furthermore, the increase of $\mathrm{C} \overline{\mathrm{S}}$ content results in the increase of Debye length and leads to the increases of zeta potential.

Therefore, larger CSA content in ternary system results in longer Debye length but lower zeta potential,

312 while higher proportion of $\bar{C} \bar{S}$ contributes to larger value of Debye length and higher and zeta potential.

Table 5 Electro-kinetic parameters of diluted $\mathrm{C} \overline{\mathrm{S}}$, OPC, CSA paste and their binary blends

\begin{tabular}{ccccc}
\hline Samples & $\begin{array}{c}\zeta \\
(\mathrm{mV})\end{array}$ & $\begin{array}{c}\text { Debye length } \\
(\mathrm{nm})\end{array}$ & $\begin{array}{c}\text { Conductivity } \\
(\mathrm{mS} / \mathrm{cm})\end{array}$ & $\mathrm{pH}$ value \\
\hline Only $\mathrm{C} \overline{\mathrm{S}}$ & 2.31 & 1.61 & 5.33 & 6.89
\end{tabular}




\begin{tabular}{ccccc} 
Only OPC & 3.13 & 1.25 & 8.06 & 13.09 \\
$5-10 / 0$ & 2.40 & 1.12 & 10.05 & 12.82 \\
$10-10 / 0$ & 2.16 & 1.92 & 3.44 & 12.56 \\
Only CSA & 0.47 & 2.70 & 1.74 & 12.41 \\
$5-0 / 10$ & 0.46 & 1.54 & 5.33 & 12.31 \\
$10-0 / 10$ & 2.13 & 3.70 & 0.94 & 12.48 \\
\hline
\end{tabular}

Table 6 Electro-kinetic parameters of diluted OPC-CSA-C $\bar{S}$ pastes

\begin{tabular}{|c|c|c|c|c|c|c|c|c|}
\hline \multirow{2}{*}{$\begin{array}{c}\mathrm{OPC} / \mathrm{CS} \\
\text { A mass } \\
\text { ratio } \\
\end{array}$} & \multicolumn{4}{|c|}{$5 \% \mathrm{C} \bar{S}$} & \multicolumn{4}{|c|}{$10 \% \mathrm{C} \bar{S}$} \\
\hline & $\begin{array}{c}\zeta \\
(\mathrm{mV}) \\
\end{array}$ & $\begin{array}{l}\text { Debye length } \\
(\mathrm{nm})\end{array}$ & $\begin{array}{c}\text { Conductivity } \\
(\mathrm{mS} / \mathrm{cm})\end{array}$ & $\begin{array}{c}\mathrm{pH} \\
\text { value }\end{array}$ & $\begin{array}{c}\zeta \\
(\mathrm{mV}) \\
\end{array}$ & $\begin{array}{c}\text { Debye length } \\
(\mathrm{nm})\end{array}$ & $\begin{array}{c}\text { Conductivity } \\
(\mathrm{mS} / \mathrm{cm})\end{array}$ & $\begin{array}{c}\mathrm{pH} \\
\text { value } \\
\end{array}$ \\
\hline $9 / 1$ & 2.14 & 1.19 & 8.92 & 12.93 & 4.46 & 2.44 & 2.48 & 12.87 \\
\hline $8 / 2$ & 2.46 & 1.19 & 8.97 & 12.67 & 3.52 & 2.78 & 2.60 & 12.57 \\
\hline $7 / 3$ & 1.62 & 1.33 & 7.08 & 12.29 & 2.87 & 2.86 & 2.51 & 12.44 \\
\hline $6 / 4$ & 1.63 & 1.35 & 6.82 & 12.11 & 2.45 & 3.03 & 2.39 & 12.28 \\
\hline $5 / 5$ & 1.12 & 1.44 & 5.99 & 12.16 & 1.82 & 3.13 & 2.27 & 12.43 \\
\hline $4 / 6$ & 0.45 & 1.64 & 4.67 & 12.01 & 1.35 & 3.45 & 2.07 & 12.29 \\
\hline $3 / 7$ & -0.23 & 1.89 & 3.52 & 11.95 & 0.72 & 2.45 & 2.18 & 12.17 \\
\hline $2 / 8$ & 0.39 & 1.95 & 2.68 & 12.02 & 0.66 & 2.59 & 2.94 & 12.06 \\
\hline $1 / 9$ & 0.47 & 2.03 & 2.34 & 11.88 & 0.63 & 2.45 & 2.46 & 12.14 \\
\hline
\end{tabular}

\subsection{Evolution of static yield stress with resting time}

319 The static yield stress vs. resting time curves of OPC pastes and CSA cement paste with different 320 contents of $\overline{C S}$ were given in Fig. 5. Perrot's model was employed to fit these data and the result is

321 given in Table 7. The result shows that the C $\bar{S}$ influences the static yield stress of the OPC paste and 322 CSA cement paste differently. For the OPC pastes, $5 \%$ of C $\bar{S}$ reduces the initial yield stress $\tau_{0,0}$, while 323 the $\tau_{0,0}$ is higher when the dosage of $C \bar{S}$ is $10 \%$. After longer resting time, the increase of yield stress 324 at $10 \% \mathrm{C} \overline{\mathrm{S}}$ is indicating a significant increase of setting time. On the contrary, the incorporation of $\mathrm{C}$ $325 \overline{\mathrm{S}}$ significantly increases not only the $\tau_{0,0}$ value but also the structural build-up rate $\mathrm{A}_{\text {thix }}$ of CSA cement 326 paste comparing to the sample without $\mathrm{C} \overline{\mathrm{S}}$. However, no difference in $\mathrm{A}_{\text {thix }}$ value of CSA cement paste 327 is observed between samples with $5 \%$ and $10 \% \mathrm{C} \overline{\mathrm{S}}$. 
(a) OPC paste

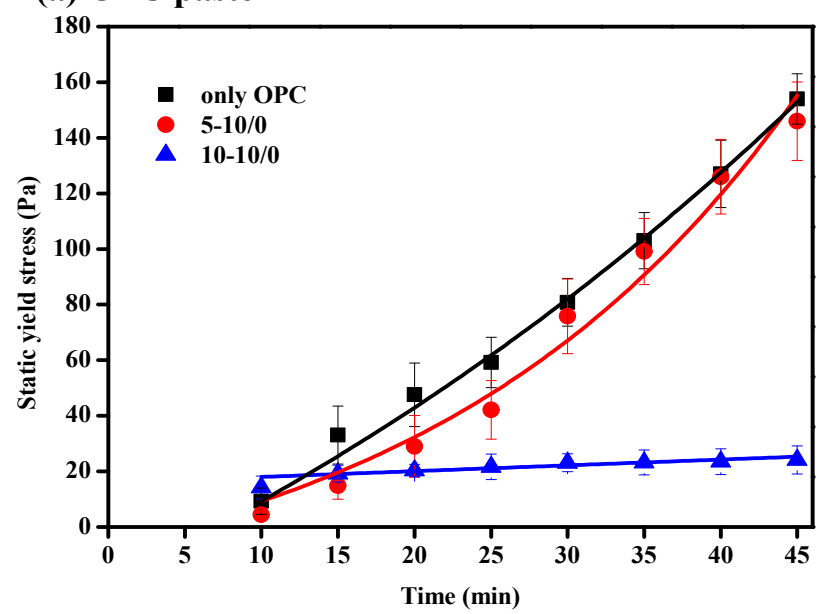

(b) CSA paste

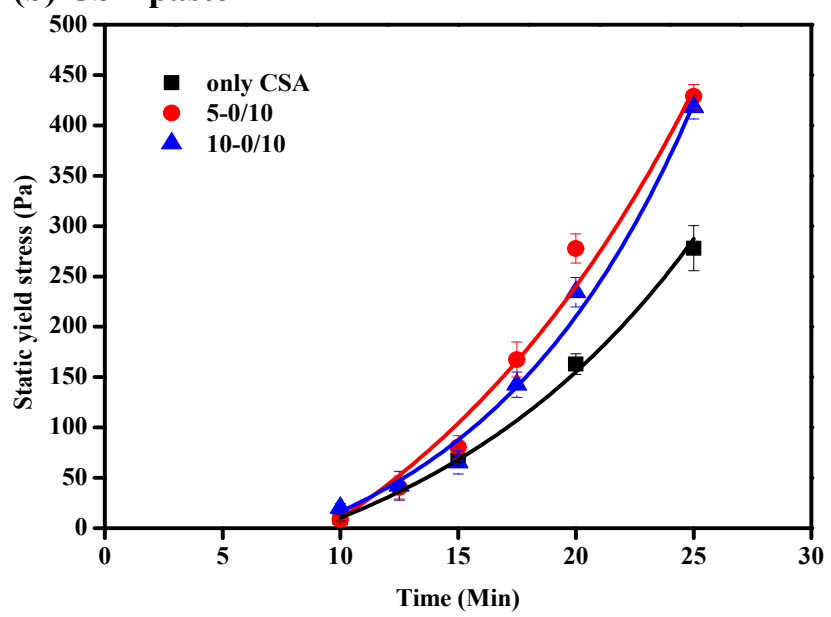

Fig. 5 The influence of $C \bar{S}$ on the evolution of static yield stress of OPC and CSA paste with resting time

Table 7 Effect of CS content on the structural build-up parameters of OPC paste and CSA paste obtained from Perrot model

\begin{tabular}{ccccc}
\hline Samples & $\begin{array}{c}\tau_{0,0} \\
(\mathrm{~Pa})\end{array}$ & $\begin{array}{c}\mathrm{A}_{\text {thix }} \\
(\mathrm{Pa} / \mathrm{min})\end{array}$ & $\begin{array}{c}\mathrm{t}_{\mathrm{c}} \\
(\mathrm{min})\end{array}$ & $\mathrm{R}^{2}$ \\
\hline Only OPC & 9.65 & 3.118 & 66.488 & 0.9966 \\
$5-10 / 0$ & 7.73 & 1.860 & 24.237 & 0.9663 \\
$10-10 / 0$ & 14.01 & 0.209 & 1249.089 & 0.9293 \\
Only CSA & 6.142 & 9.306 & 12.072 & 0.9925 \\
$5-0 / 10$ & 9.202 & 15.450 & 14.915 & 0.9875 \\
$10-0 / 10$ & 11.256 & 14.709 & 9.182 & 0.9821 \\
\hline
\end{tabular}

Fig. 6 plots the evolution curves of static yield stress of ternary OPC-CSA-C $\bar{S}$ blends. The structural build-up rate was calculated by Perrot's model as well. The results are listed in Table 8 . It shows a well fit between Perrot's model and experimental data of ternary blends. As can be seen in Table 8, the proportions of OPC, CSA and C $\bar{S}$ affects the structural build-up of blends greatly. The initial yield stress $\tau_{0,0}$ of blends is increased with the CSA content and C $\bar{S}$ content. The higher CSA proportion is of benefit for structuration of blends. However, at the same OPC/CSA ratio, $A_{\text {thix }}$ value of those with $10 \% \mathrm{C} \overline{\mathrm{S}}$ is always higher than that of those with $5 \% \mathrm{C} \overline{\mathrm{S}}$. Particularly, when OPC/CSA ratio is lower 
than $6 / 4$, the structural build-up rates of blends containing $10 \% \mathrm{C} \bar{S}$ have quadrupled in that of blends with $5 \% \mathrm{C} \bar{S}$. It reveals that the higher percentage of $\mathrm{C} \bar{S}$ conduces to structural build-up of ternary blends, which is contrary to the result for CSA cement paste and OPC paste. It should be noted that when the OPC/CSA ratio drops to $1 / 9$, the $\mathrm{A}_{\text {thix }}$ of ternary composite cement paste with $5 \% \mathrm{C} \overline{\mathrm{S}}$ is over 343 that of binary CSA $+\mathrm{C} \bar{S}$ paste; and for $10 \%$ of $\mathrm{C} \bar{S}$ content, the build-up rate of the blend with only $7 / 3$ of $\mathrm{OPC} / \mathrm{CSA}$ ratio is already quicker than that of $\mathrm{CSA}+\mathrm{C} \bar{S}$ paste.

Therefore, the increase of CSA content accelerates the structural build-up of ternary blends at rest. The incorporation of $\mathrm{C} \bar{S}$ is in favor of the re-structuration of ternary blends, and it becomes more significantly when CSA dominates.

(a) with $5 \% \mathrm{C} \overline{\mathrm{S}}$

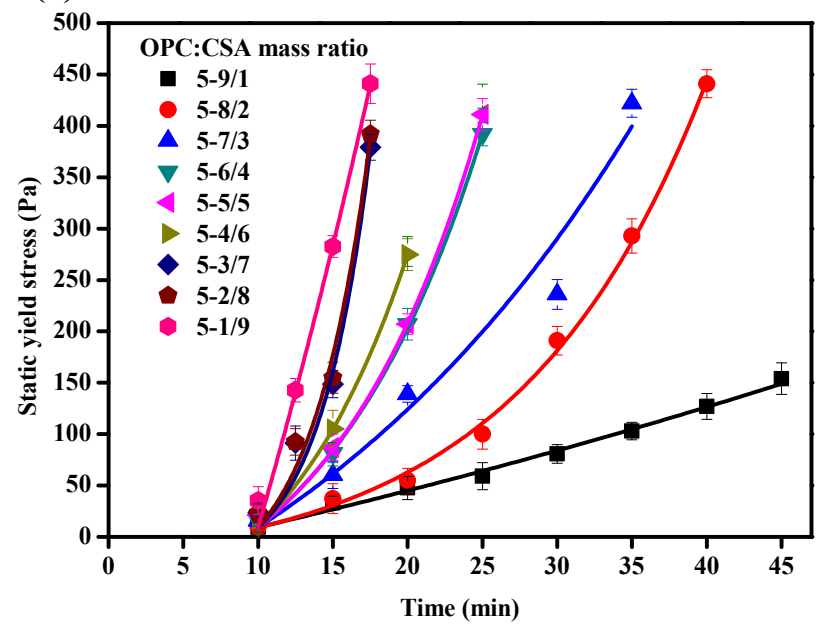

(b) with $10 \% \mathrm{C} \overline{\mathrm{S}}$

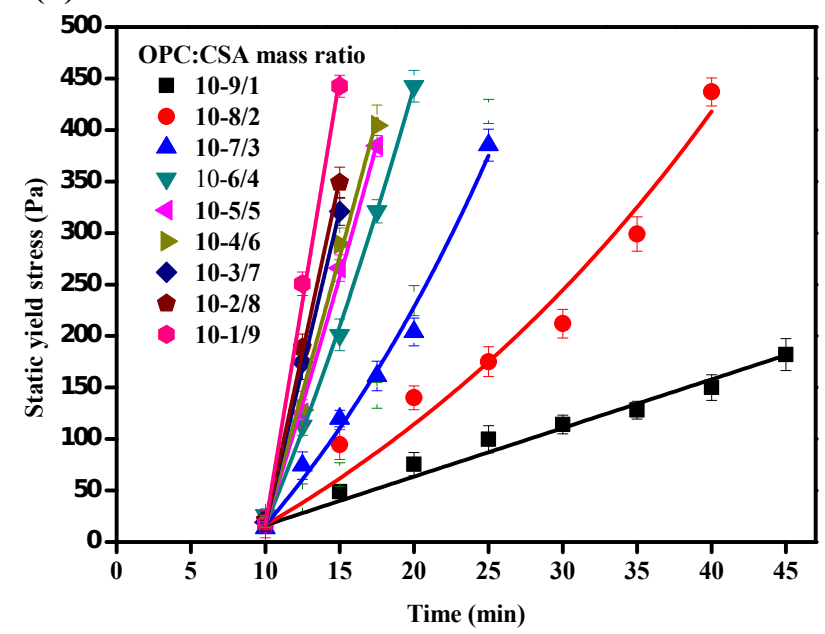

Fig. 6 Effect of OPC/CSA mass ratio on structural build-up of blends 
Table 8 The structural build-up parameters of OPC-CSA-C $\bar{S}$ pastes obtained from Perrot's model

\begin{tabular}{|c|c|c|c|c|c|c|c|c|}
\hline \multirow{2}{*}{$\begin{array}{l}\mathrm{OPC} / \mathrm{CSA} \\
\text { mass ratio }\end{array}$} & \multicolumn{4}{|c|}{$5 \% \mathbf{C} \overline{\mathbf{S}}$} & \multicolumn{4}{|c|}{$10 \% \mathbf{C} \overline{\mathbf{S}}$} \\
\hline & $\begin{array}{c}\tau_{0,0} \\
(\mathrm{~Pa})\end{array}$ & $\begin{array}{c}\mathrm{A}_{\text {thix }} \\
(\mathrm{Pa} / \mathrm{min})\end{array}$ & $\begin{array}{c}t_{c} \\
(\min )\end{array}$ & $\mathrm{R}^{2}$ & $\begin{array}{c}\tau_{0,0} \\
(\mathrm{~Pa})\end{array}$ & $\begin{array}{c}\mathrm{A}_{\text {thix }} \\
(\mathrm{Pa} / \mathrm{min})\end{array}$ & $\begin{array}{c}t_{c} \\
(\mathrm{~min})\end{array}$ & $\mathrm{R}^{2}$ \\
\hline $9 / 1$ & 9.273 & 3.506 & 12.579 & 0.9982 & 16.069 & 4.723 & 15.707 & 0.9810 \\
\hline $8 / 2$ & 8.911 & 9.499 & 27.069 & 0.9696 & 17.116 & 8.456 & 34.938 & 0.9793 \\
\hline $7 / 3$ & 9.014 & 11.703 & 10.709 & 0.9980 & 16.055 & 16.831 & 9.182 & 0.9921 \\
\hline $6 / 4$ & 9.421 & 11.649 & 10.120 & 0.9925 & 16.921 & 35.290 & 27.356 & 0.9961 \\
\hline $5 / 5$ & 9.252 & 13.329 & 10.071 & 0.9974 & 16.859 & 46.051 & 55.143 & 0.9983 \\
\hline $4 / 6$ & 9.433 & 14.217 & 8.759 & 0.9804 & 17.021 & 51.176 & 133.363 & 0.9950 \\
\hline $3 / 7$ & 9.625 & 16.360 & 3.390 & 0.9794 & 17.152 & 61.136 & 213.814 & 0.9989 \\
\hline $2 / 8$ & 10.752 & 16.392 & 3.385 & 0.9760 & 18.044 & 67.226 & 119.159 & 0.9974 \\
\hline $1 / 9$ & 12.564 & 50.503 & 30.010 & 0.9856 & 20.210 & 87.001 & 108.182 & 0.9908 \\
\hline
\end{tabular}

\subsection{Hydration kinetics and phase changes}

\subsubsection{Hydration heat}

359 Calorimetric testing results of OPC-CSA-C $\bar{S}$ blends are given in Fig. 7. As can be seen in the figure, 360 the hydration of OPC $+\mathrm{C} \bar{S}$ paste is still in the induction period when it is subjected to the rheology 361 test. The higher percentage of $\mathrm{C} \bar{S}$ slightly retards the induction period and reduces the heat releasing 362 rate in that period. In contrast, there is no obvious induction period for the CSA+C $\bar{S}$ paste, whereas 363 the rheology test period is within the accelerating period of hydration. During the rheology test period, 364 the heat flow value of $\mathrm{CSA}+10 \% \mathrm{C} \overline{\mathrm{S}}$ is significantly higher than $\mathrm{CSA}+5 \% \mathrm{C} \overline{\mathrm{S}}$ paste. The main peak 365 of heat flow of $\mathrm{CSA}+10 \% \mathrm{C} \overline{\mathrm{S}}$ blend occurs earlier than that of the blend with $5 \% \mathrm{C} \overline{\mathrm{S}}$. It is agreed 366 with Refs. $[13,14]$ that the existence of $C \bar{S}$ accelerates the hydration of CSA, but it delays the 367 hydration of OPC.

369 For the ternary OPC-CSA-C $\bar{S}$ systems, the hydration heat is influenced by OPC/CSA ratio as well as 
$370 \mathrm{C} \overline{\mathrm{S}}$ content. When OPC is blended with CSA, it becomes more difficult to distinguish the induction period and the accelerating period, particularly at higher OPC/CSA ratio. The decrease of OPC/CSA ratio makes the main peak (i.e. silicate reaction [13]) occur earlier and causes a higher heat releasing rate during rheology test. When $\mathrm{C} \overline{\mathrm{S}}$ content is $5 \%$ and $\mathrm{OPC} / \mathrm{CSA}$ ratio drops to $6 / 4$ or lower, the heat 374 flow value including peak value of ternary pastes outnumbers the $C S A+C \bar{S}$, and accelerating period is also shortened. However, the larger $\mathrm{C} \overline{\mathrm{S}}$ proportion performs an opposite effect. It reduces the heat flow values and delays the peak occurrence.

According to calorimetric data, it can be concluded that the higher CSA content is, the more rapid reaction rate is. Moreover, $\mathrm{C} \overline{\mathrm{S}}$ retards the hydration of ternary system. The difference of hydration heat releasing rate reveals the difference of hydrates kinetics in cement pastes. ternary paste is observed with reducing the OPC/CSA ratio. The $\mathrm{K}_{\mathrm{G}}$ value of the ternary blends is 
393 Moreover, the $\mathrm{K}_{\mathrm{N}}$ value of ternary blends is also higher than that of $\mathrm{OPC}+\mathrm{C} \overline{\mathrm{S}}$ paste. The $\mathrm{K}_{\mathrm{N}}$ value is 394 improved by more than an order of magnitude at higher CSA content. When the proportion of CSA is 395 more than $60 \%$ of composite cement, the $\mathrm{K}_{\mathrm{N}}$ value is even larger than that of $\mathrm{CSA}+\mathrm{C} \overline{\mathrm{S}}$ paste.

397 As shown in Table 9, the $\mathrm{K}_{\mathrm{G}}$ value of $\mathrm{OPC}+\mathrm{C} \overline{\mathrm{S}}$ blend remains nearly unchanged with the increase of $398 C \bar{S}$ content, however, the $K_{N}$ value decreases. In contrast, the $K_{N}$ and $K_{G}$ values of CSA cement system 399 are both increased at higher $\mathrm{C} \overline{\mathrm{S}}$ content. However, the effect of $\mathrm{C} \overline{\mathrm{S}}$ content on the hydration kinetics 400 of ternary $\mathrm{OPC}+\mathrm{CSA}+\mathrm{C} \overline{\mathrm{S}}$ system depends on the OPC/CSA ratio. When OPC/CSA ratio is greater 401 than $8 / 2$, the $\mathrm{K}_{\mathrm{G}}$ values of those with $5 \% \mathrm{C} \overline{\mathrm{S}}$ are higher than that of those with $10 \% \mathrm{C} \overline{\mathrm{S}}$. Opposite 402 result is observed when the OPC/CSA value is lower than $8 / 2$. When the content of OPC is larger than 403 the content of CSA, the $\mathrm{K}_{\mathrm{N}}$ values of blends with $5 \% \mathrm{C} \overline{\mathrm{S}}$ is greater than that of those with $5 \% \mathrm{C} \overline{\mathrm{S}}$. 404 However, the former is smaller than the later when CSA dominates.

406 The results of hydration heat flow and hydration kinetics suggest that the presence of CSA accelerates 407 the hydration evolution of ternary system, and increases the nucleation and growth kinetics of hydrates 408 at structural build-up period. The addition of $\bar{C} \bar{S}$ retards the hydration of ternary system while it further 409 improves the hydration kinetics of nucleation and growth kinetics of hydrates at higher CSA content. 
(a) with $5 \% \mathbf{C} \overline{\mathbf{S}}$

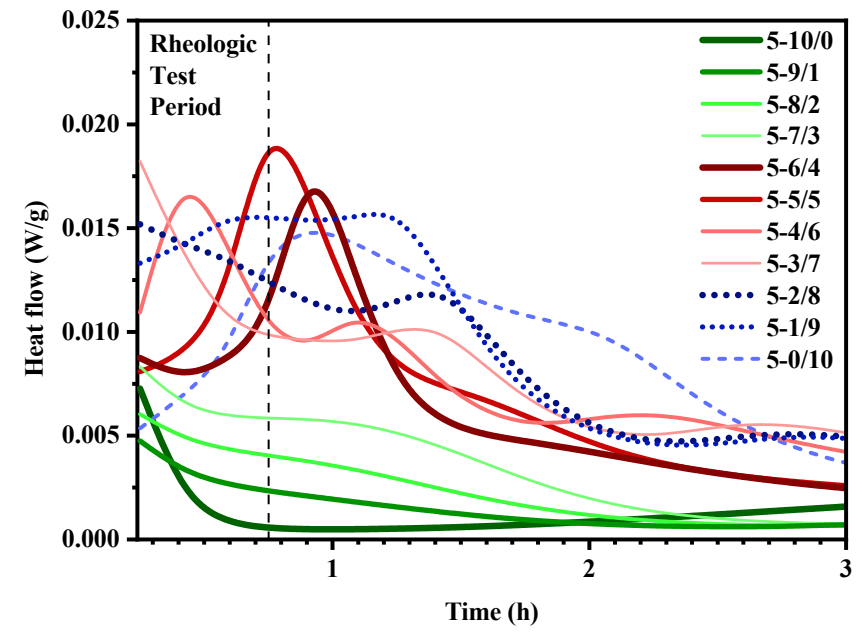

(b) with $10 \% \mathrm{C} \overline{\mathrm{S}}$

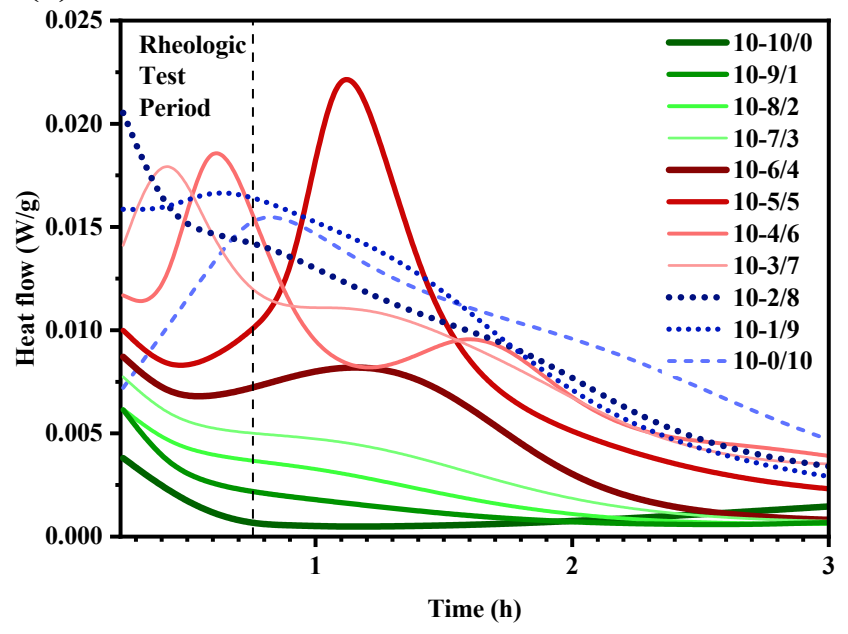

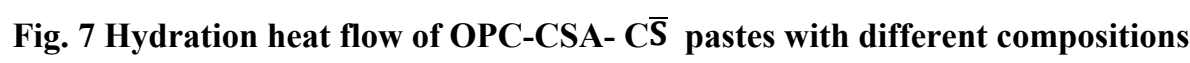

Table 9 Estimated surface area of cement particles per unit volume of paste and hydration kinetic parameters obtained from BNG model

\begin{tabular}{|c|c|c|c|c|c|c|}
\hline \multirow{2}{*}{$\begin{array}{l}\mathrm{OPC} / \mathrm{CSA} \\
\text { mass ratio }\end{array}$} & \multicolumn{3}{|c|}{$5 \% \mathbf{C} \overline{\mathbf{S}}$} & \multicolumn{3}{|c|}{$10 \% \mathbf{C} \overline{\mathbf{S}}$} \\
\hline & $\begin{array}{c}S \\
\left(\mu \mathrm{m}^{-1}\right)\end{array}$ & $\begin{array}{c}\mathrm{K}_{\mathrm{G}} \\
\left(\mathrm{h}^{-1}\right)\end{array}$ & $\begin{array}{c}\mathrm{K}_{\mathrm{N}} \\
\times 10^{-3}\left(\mathrm{~h}^{-3}\right)\end{array}$ & $\begin{array}{c}S \\
\left(\mu \mathrm{m}^{-1}\right)\end{array}$ & $\begin{array}{l}\mathrm{K}_{\mathrm{G}} \\
\left(\mathrm{h}^{-1}\right)\end{array}$ & $\begin{array}{c}\mathrm{K}_{\mathrm{N}} \\
\times 10^{-3}\left(\mathrm{~h}^{-3}\right)\end{array}$ \\
\hline $10 / 0$ & 0.9170 & 0.0239 & 0.0045 & 0.9363 & 0.0204 & 0.0027 \\
\hline $9 / 1$ & 0.9875 & 0.1338 & 0.0082 & 1.0035 & 0.0300 & 0.0037 \\
\hline $8 / 2$ & 1.0596 & 0.1780 & 0.0399 & 1.0721 & 0.1382 & 0.0013 \\
\hline $7 / 3$ & 1.1333 & 0.2238 & 0.0143 & 1.1422 & 0.2221 & 0.0065 \\
\hline $6 / 4$ & 1.2087 & 0.2260 & 3.2807 & 1.2139 & 0.2493 & 0.0230 \\
\hline $5 / 5$ & 1.2859 & 0.2362 & 4.2843 & 1.2871 & 0.2690 & 5.3107 \\
\hline $4 / 6$ & 1.3649 & 0.2211 & 4.0999 & 1.3619 & 0.2438 & 4.1734 \\
\hline $3 / 7$ & 1.4457 & 0.2125 & 3.1934 & 1.4384 & 0.2532 & 3.9167 \\
\hline $2 / 8$ & 1.5285 & 0.2568 & 3.7903 & 1.5167 & 0.3049 & 4.5137 \\
\hline $1 / 9$ & 1.6134 & 0.3001 & 4.7083 & 1.5967 & 0.3353 & 4.0898 \\
\hline $0 / 10$ & 1.7003 & 0.2417 & 3.1832 & 1.6786 & 0.2719 & 3.7654 \\
\hline
\end{tabular}

\subsubsection{XRD analysis and DTG results}

414 In order to reveal the hydrates formed during the rheological test period, the XRD analysis and DTA

415 analysis were carried out to characterize the solid phase in ternary blends during $10 \sim 30$ min. Fig. 8 
416 plots the XRD results of blends with different OPC/CSA ratios and $\bar{C} \bar{S}$ contents at 15 min and 30 min.

417 It can be seen a very weak diffraction peak of calcium silicate hydrate occurs at 15 min in both two

418 XRD patterns of OPC $+\mathrm{C} \bar{S}$ pastes in addition to the strong $\mathrm{C} \overline{\mathrm{S}}$ peak. No significant changes in the

419 XRD patterns are observed for OPC $+\mathrm{C} \overline{\mathrm{S}}$ pastes from $15 \mathrm{~min}$ to $30 \mathrm{~min}$. Ettringite and gypsum are the

420 main hydrates formed in both $\mathrm{CSA}+5 \% \mathrm{C} \overline{\mathrm{S}}$ and $\mathrm{CSA}+10 \% \mathrm{C} \overline{\mathrm{S}}$ pastes according to XRD data. It can

421 be clearly observed that the AFt peaks become stronger with time. However, the gypsum peaks become

422 weaker from 15 min to $30 \mathrm{~min}$. It can also be seen that both calcium silicate hydrate and ettringite are

423 formed in ternary $\mathrm{OPC}+\mathrm{CSA}+\mathrm{C} \overline{\mathrm{S}}$ pastes. The peak intensity of AFt increases with time, while the

424 intensity of the peak relates to gypsum is reduced. The influences of OPC/CSA ratio on the peak

425 intensity of ettringite and CSH are opposite. The peaks of OPC and CSA hydrates in ternary composite

426 pastes are sharper than those in $\mathrm{OPC}+\mathrm{C} \overline{\mathrm{S}}$ and $\mathrm{CSA}+\mathrm{C} \overline{\mathrm{S}}$ pastes. The lower OPC/CSA ratio results in

427 much stronger ettringite peaks while corresponding weaker CSH peaks in ternary cement pastes.

428 Furthermore, the increasing content of $\mathrm{C} \overline{\mathrm{S}}$ leads to sharper peaks of ettringite and $\mathrm{CSH}$. This positive

429 effect of $\mathrm{C} \overline{\mathrm{S}}$ becomes more significant with time. 

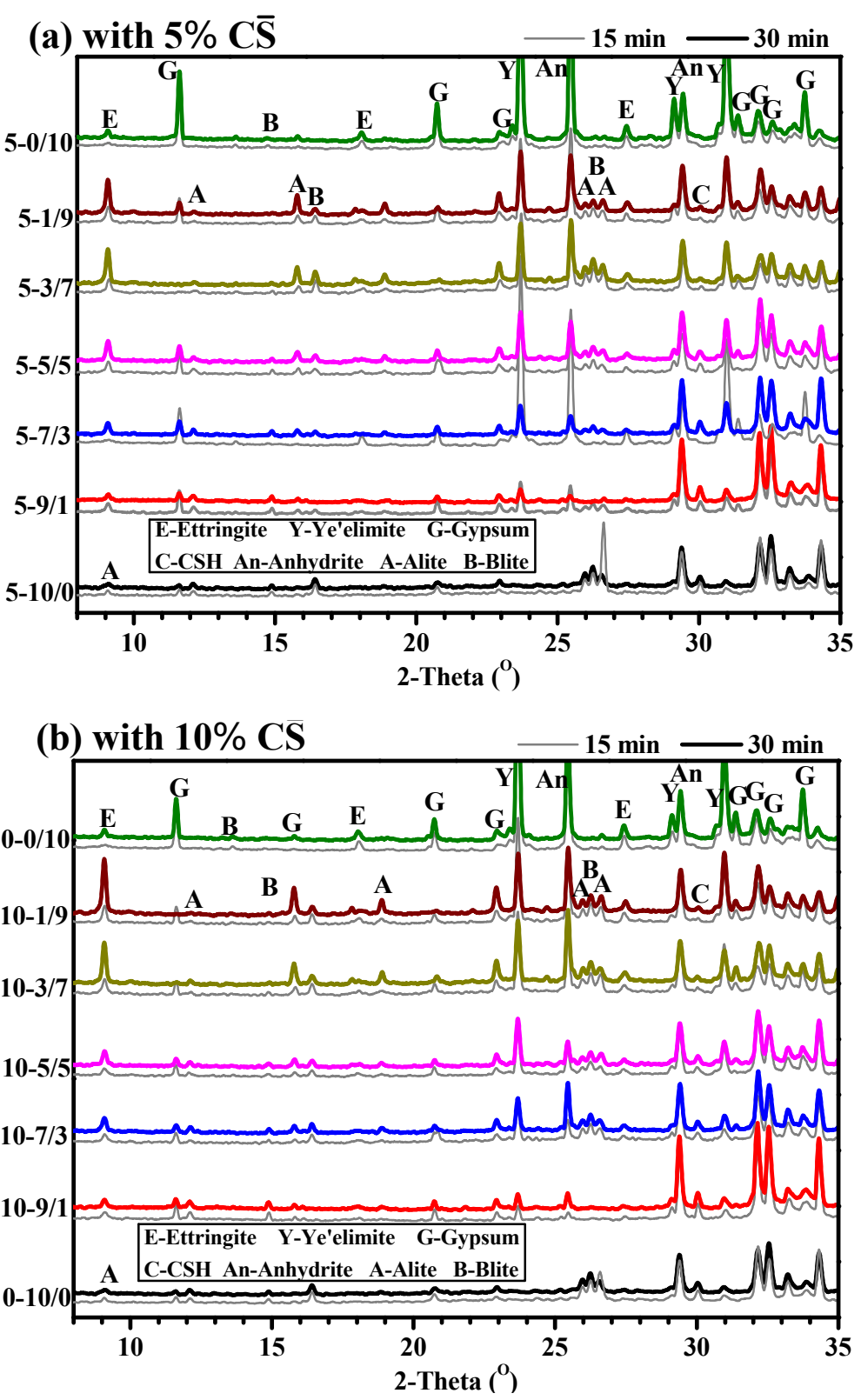

Fig. 8 The XRD patterns of OPC-CSA-C $\bar{S}$ pastes with different compositions at $15 \mathrm{~min}$ (below curve) and 30 min (upper curve). E: Ettringite (PDF\# 41-1451), Y: Ye'elimite (PDF\# 33-0256), G: Gypsum (PDF\# 330311), $\mathrm{C}$ : calcium silicate hydrate $\left(\mathrm{Ca}_{2} \mathrm{SiO}_{4} \cdot \mathbf{0 . 3 5}_{2} \mathrm{O}\right.$ [PDF\# 15-0641], $\mathrm{Ca}_{2} \mathrm{SiO}_{4} \cdot \mathrm{H}_{2} \mathrm{O}$ [PDF\# 03-0594], $\mathrm{Ca}_{1.5} \mathrm{SiO}_{3.5} \cdot \mathrm{xH}_{2} \mathrm{O}$ [PDF\# 33-0306]), An: Anhydrite (PDF\# 37-1496), A: Alite (PDF\# 49-0442), B: $\beta$-Blite (PDF\# 35-0642)

432 The TGA analyses shown in Fig. 9 and Fig. 10 confirm the observations from XRD. Fig. 9 shows the 433 DTG curves of the samples after 30 min of hydration. Two major peaks are observed for the OPC $+\mathrm{C}$ $434 \overline{\mathrm{S}}$ blends. The weight loss between $85 \sim 95{ }^{\circ} \mathrm{C}$ is attributed to the decomposition of CSH and/or 435 ettringite. The second peak between $100 \sim 130{ }^{\circ} \mathrm{C}$ is due to decomposition of gypsum. Similar results 
are also obtained for the $\mathrm{CSA}+\mathrm{C} \overline{\mathrm{S}}$ blends, where the peak around $100^{\circ} \mathrm{C}$ is mainly due to the presence of ettringite according to XRD analysis. For the $\mathrm{OPC}+\mathrm{CSA}+\mathrm{C} \overline{\mathrm{S}}$ blends, it can be observed that two peaks present in the curves of those with high OPC/CSA ratio and lower content of $\bar{C}$, while three peaks occur in the curves of those with low OPC/CSA ratio or high content of $\bar{C} \bar{S}$. In addition to 440 gypsum, ettringite and $\mathrm{CSH}$, observed for all samples, the peak between $230 \sim 250{ }^{\circ} \mathrm{C}$ is associated with 441 the decomposition of amorphous or micro-crystalline aluminum hydroxide $\left(\mathrm{AH}_{3}\right)$ according to the 442 published studies $[13,66]$.

444 Moreover, it can be seen that the peak intensity for CSH/AFt and gypsum is increasing with the 445 decrease of OPC/CSA ratio. This is attributed to the larger extent of CSH/ettringite and gypsum 446 formation when the proportion of CSA is higher. In case of blends with $10 \% \mathrm{C} \overline{\mathrm{S}}$, the intensity of $\mathrm{AH}_{3}$ 447 peak also becomes stronger with the increasing amount of CSA. an increasing trend over time for samples with $10 \% \mathrm{C} \overline{\mathrm{S}}$, however for the samples with $5 \% \mathrm{C} \overline{\mathrm{S}}$, no changes seem to be observed during 10 30 min. The results suggest the continuous increase on the amount of $\mathrm{AH}_{3}, \mathrm{AFt}$ and $\mathrm{CSH}$ during the rheological test period. Besides, gypsum was formed before $10 \mathrm{~min}$ and the amount is not increased during that period if the $\mathrm{C} \overline{\mathrm{S}}$ was low. It can also be observed from Fig 10 that the ternary system with $10 \% \mathrm{C} \overline{\mathrm{S}}$ exhibits the greater peak in the range of $80 \sim 110{ }^{\circ} \mathrm{C}$ compared to system with same OPC/CSA ratio but 5\% C $\bar{S}$. It confirms the XRD result that the incorporation of $\mathrm{C} \overline{\mathrm{S}}$ favors the formation of $\mathrm{AFt}$ and $\mathrm{CSH}$. 
459 In summary, the XRD and DTA results indicated that compounding OPC and CSA not only accelerates

460 the silicate reaction but also the aluminate reactions at very early hydration stage, which is in

461 agreement with the conclusion of Ref. [13]. The gypsum, CSH and AFt are formed in a ternary system

462 during the structural build-up period and the formation extent of those hydrates changes the whole

463 time. The higher amounts of CSA and anhydrate tends to form CSH and AFt, as well as gypsum.

(a) with 5\% C $\overline{\text {, }}$, $30 \mathrm{~min}$

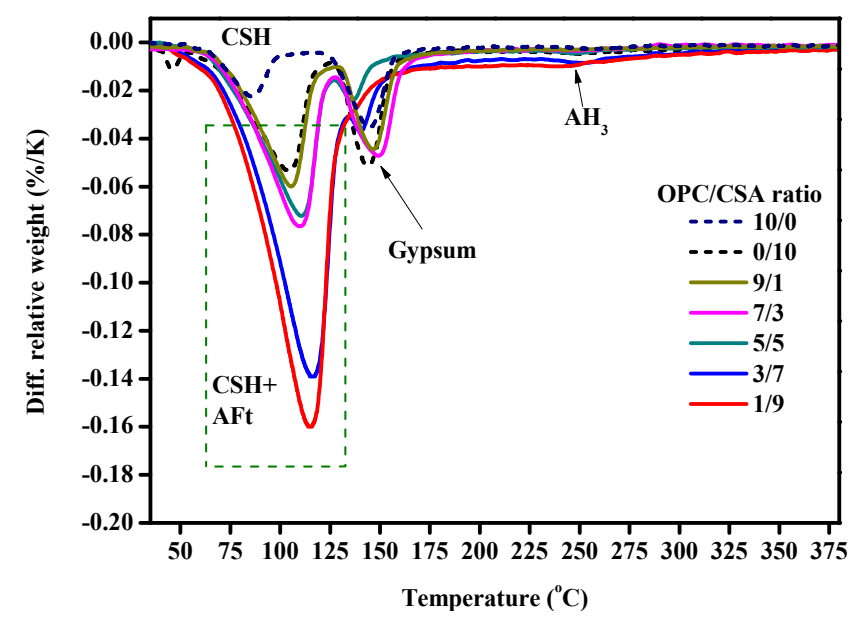

(b) with $10 \% \mathrm{C} \overline{\mathrm{S}}, @ 30 \mathrm{~min}$

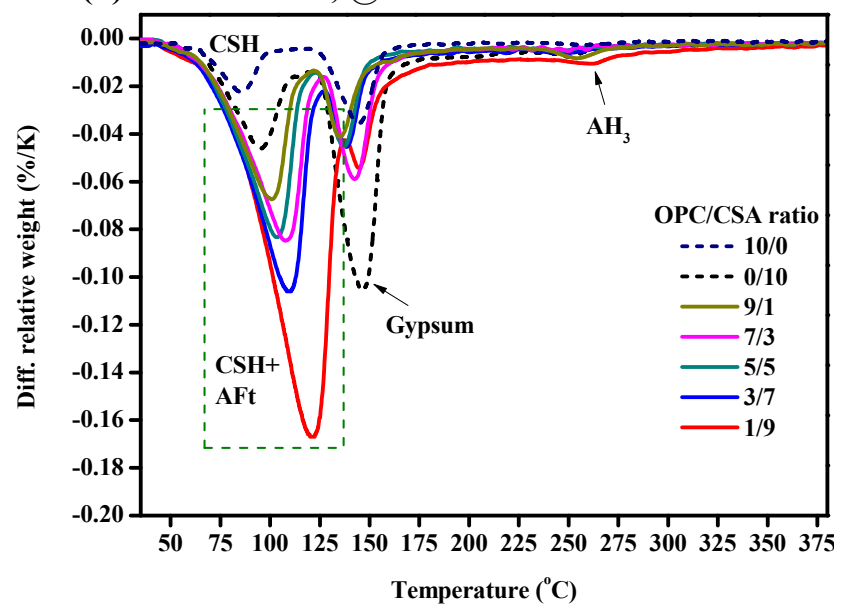

Fig. 9 The TGA plots of OPC-CSA-C $\bar{S}$ pastes with different compositions at $30 \mathrm{~min}$

(a)OPC/CSA ratio=9/1

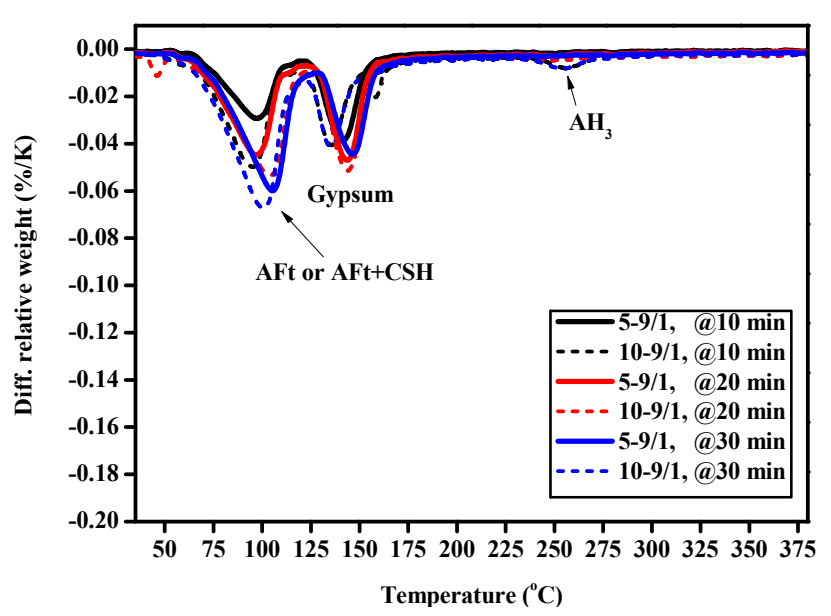

(b)OPC $/ \mathrm{CSA}$ ratio $=5 / 5$

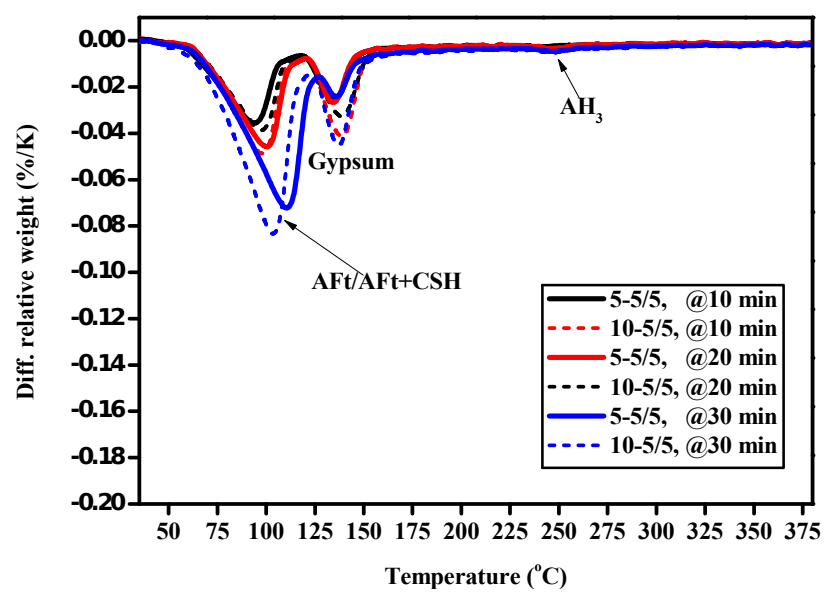


(c)OPC/CSA ratio=1/9

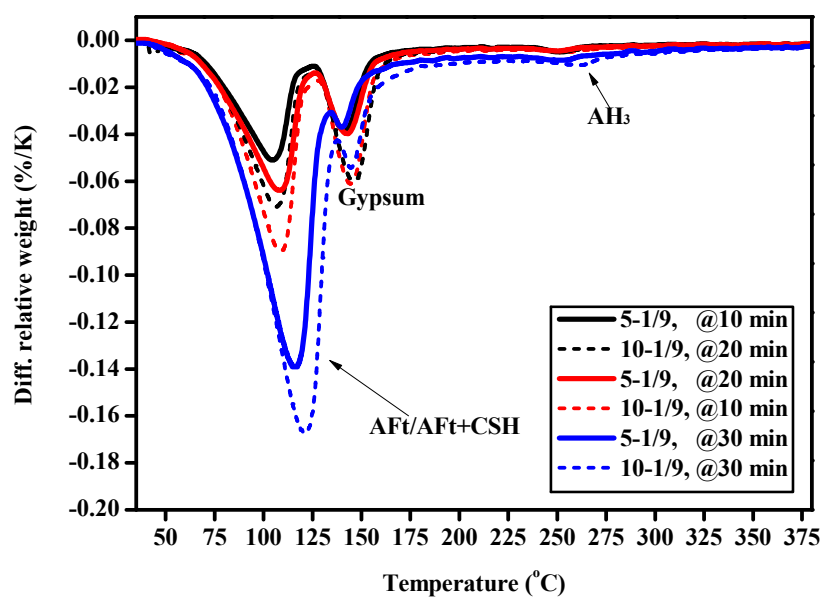

Fig. 10. The DTG data of ternary blends over time

\section{Discussion}

467 The initial and time-dependent rheological parameters of Portland clinker-calcium sulphoaluminate clinker-anhydrite blends are closely related to their relative contents. According to the present study,

469 it has been proved that the proportion of these three components affects the electro-kinetics of blend,

470 which determines colloidal electrostatic interaction of particles in a ternary system. Besides, the 471 relative amounts of three components also influences the assemblage and formation rate of hydrates 472 in the ternary system, which is mainly responsible for the structure and the rigidity of fresh cement 473 paste. This section compares the correlation between electro-kinetics, hydration kinetics and the 474 evolution of rheological parameters of ternary blends. It aims to discuss how the rheology of OPC475 CSA-C $\bar{S}$ blend is controlled by the physical action and hydration. 478 of OPC-CSA-C $\bar{S}$ ternary blend

479 The dynamic yield stress of cementitious materials originates from the colloidal interaction and direct 
contact between particles [67]. It is important in quantifying flowability and is related to the slump and slump flow test in field [68 70]. It was noted that the higher dynamic yield stress is, the poorer the flowability is.

According to above-mentioned results, the increase of CSA content slightly increases the dynamic yield stress of fresh ternary OPC-CSA-C $\bar{S}$ blends and significantly increases their viscosity. It means that enlarging CSA content causes the loss of flowability.

Initial rheological feature of fresh paste relates strongly to the solid volume fraction. As shown in

Table 2, the increase of CSA content increases the solid volume fraction of ternary blend at constant mass ratio, which is one of the reasons for increasing dynamic yield stress [71, 72]. Additionally, it can be seen in Table 9, in case of ternary blends, the estimated surface area of particles per volume (S) is enlarged significantly with the increase of CSA content. It also has positive effect on increasing yield stress and viscosity [24, 75]. Besides, surface interactions and hydration occurring in blend also 494 should be responsible.

The surface interactions consist in a fresh blend of two opposing forces, the attractive van der Waals and the repulsive electrical double layer force. The electrical double layer force is a function of the square value of zeta potential $\left(\zeta^{2}\right)$. Namely, the larger $\zeta^{2}$ is, the larger the electrical double layer force is [65]. According to results shown in section 3.2, the increase of CSA content reduces the $\zeta\left(\zeta^{2}\right)$ of blend, which means that the higher proportion of CSA weakens the repulsive electrical force between particles in blend. It makes the attraction between charged particles become easier and the attractive 
502 force become stronger [65]. When the blend is subjected to a shear force, it is more difficult to 503 overcome the interforce between particles and make them move. Thus, the dynamic yield stress 504 increases with CSA content.

506 As seen from Table 2 and Table 9, increasing $C \bar{S}$ content leads to little changes in the solid volume 507 fraction and the estimated surface area of particles per volume (S) of ternary blends. However, the 508 increase of $\mathrm{C} \overline{\mathrm{S}}$ compensates the flowability by significantly reducing the dynamic yield stress. The 509 variation of zeta potential due to the increase of $C \bar{S}$ can also explain it. According to the results, the 510 zeta potential of ternary blends with $10 \% \mathrm{C} \bar{S}$ is greater than the values of those with $5 \%$. Moreover, 511 Debye length of the former is nearly twice as that of the latter, which is also favorable for the 512 improvement of electrostatic effect between particles [65]. It means that the larger content of CS 513 increases the repulsive electrical force between particles and reduces the possibility of aggregation. It 514 is easier to break the electrostatic interaction between particles in ternary blends. Thus, C $\bar{S}$ lowers the 515 resistance of the blend to flow, which is responsible for the lower dynamic yield stress.

517 Kapur[73], Scales[74] and Johnson[75] believed that dynamic yield stress is negatively related to the $518 \zeta^{2}$ value of a suspension. Fig. 11 plots the relationship between the $\zeta^{2}$ value and dynamic yield stress 519 of ternary blends obtained by MB model and HB model. It can be observed that the dynamic yield 520 stress of the fresh blend decreases with the increase of the $\zeta^{2}$ value. In particular, the dynamic yield stress data obtained by MB model presents better correlation with $\zeta^{2}$. 


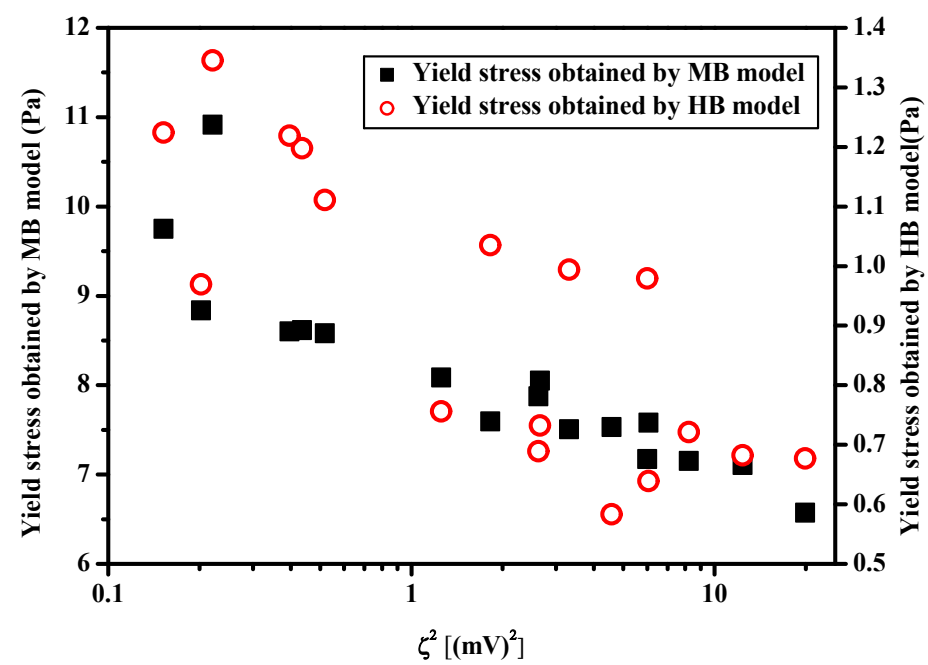

Fig. 11. The relationship between the $\zeta^{2}$ value and dynamic yield stress of ternary blends

The hydration of blends can affect the surface characteristic and solid volume fraction of blends. The coarseness of surface and volume fraction can significantly influence the initial rheological feature of the blend [24].

As shown in Table 9, blend with higher CSA content has the much higher nucleation and growth kinetics of hydrate. The quick formation of needle-like AFt crystal or denser hydrates aggregate makes the surface of cement grain become coarser, which enhances the friction between neighboring particles

530 when paste is subjected to shear force. The quicker growth of hydrate covered on the surface of 531 particles makes it more possible to increase the solid volume fraction of blend at very early stage. The higher solid volume fraction is, the larger yield stress is.

534 Likewise, the negative effect of $\mathrm{C} \overline{\mathrm{S}}$ on dynamic yield stress is also attributed to the retarding effect of $535 \mathrm{C} \overline{\mathrm{S}}$ on hydration and its negative effect on nucleation of hydrates (see Fig. 7 and Table 9). The adverse 536 effect of $\mathrm{C} \overline{\mathrm{S}}$ on hydration results in less amount of hydrates covered on the grains at very early age, 
therefore particles could easily slip and pass through under shearing. Furthermore, the increase of apparent viscosity caused by the incorporation of $C \bar{S}$ is due to the higher viscosity of $C \bar{S}$ paste than that of OPC paste and CSA cement paste $[77,78]$.

Shear-thinning and shear-thickening are shear-induced responses, and their intensities are related to the nature of paste at the same testing program [79 81]. It relates to the interparticle force and dispersed efficiency of the system. Under the variation of shear-rate between $0 \sim 100 \mathrm{~s}^{-1}$, the ternary OPC-CSA-C $\bar{S}$ blend behaves shear thinning, and the intensity increases with the content of C $\bar{S}$ and with the CSA content at higher OPC/CSA ratios. It reveals that the blends applied with a higher shear rate has a smaller size of aggregation and a lower level of flocculation. And the increase of CSA and $\mathrm{C} \overline{\mathrm{S}}$ makes this phenomenon more significant. The high shear rate may break the rigid "AFt linkage" between particles, untangled the interlock of hydrates and even polished the surface of cement grains. Because of the higher amount of "AFt linkage" in pastes with high CSA content, the sensitivity of the blends with high CSA content on shear rate is stronger. However, when the OPC/CSA ratio is lower, the faster growth of AFt makes the interaction of particle much stronger, which is difficult to break the aggregations. Therefore, the shear thinning intensity in this case becomes weaker.

\subsection{Origin of the structural build-up of OPC-CSA- C $\bar{S}$ ternary blend}

The structural build-up rate of the microstructure of fresh cement paste after casting is of importance to the multi-layer casting operations and the design of formwork [28, 41]. The structural build-up of cement suspensions is a complex phenomenon associated with the combined effect of both physical structuration due to inter-particles colloidal interactions and chemical rigidification resulting from 
cement hydration $[34,76]$. As soon as cement particles is mixed with water, the contact solution is 560 enriched with multivalent ions including cations $\left(\mathrm{Ca}^{2+}, \mathrm{K}^{+}, \mathrm{Na}^{+}, \mathrm{Al}^{3+}\right)$ and anions $\left(\mathrm{SO}_{4}^{2-}, \mathrm{OH}^{-}\right)$. Once 561 the bulk solution becomes saturated and causes the formation of ettringite-like compounds and the 562 precipitation of $\mathrm{CSH}$ on the cement surface [19]. The surface of cements and their hydration products 563 become charged either by dissociation of surface groups or adsorption of ions from the electrolyte 564 solution [82, 83]. Roussel [35] observed that this physical process takes only a few seconds. During 565 this period, the strength of the particle network is determined by the colloidal surface interactions. 566 Although these products may not yet form rigid bonds between cement particles, they do fill pore space 567 that was previously occupied by water. At a certain moment known as a percolation threshold, enough 568 particles are connected to form a continuous solid path within the fluid medium, and gradually 569 develops to a stronger skeleton. Roussel [35] attributed the rigid links between particles in OPC paste 570 in this process to metastable CSH, and named it CSH bridge. The process can take up to 100s. The 571 particle structure is further strengthened as the number and size of the hydrate bridges increase. contents are significantly altered when OPC is blended with CSA. Correspondingly, both colloidal surface interactions and rigid links between cement particles are changed.

577 In the case of ternary blend, $\mathrm{AFt}, \mathrm{CSH}$, gypsum and amorphous $\mathrm{AH}_{3}$ are formed during the rheology test period, as discussed in section 3.4.2. Thus, the structure of fresh paste is developed by the formation and growth of these hydrates. 
Fig. 12 demonstrates the networks of interacting cement particles in the structure of ternary blends.

582 Excluding the "CSH bridge", there are two main linkage in the structure of paste. One is contributed 583 by AFt crystal and another is due to the gypsum network. The morphology of AFt is generally 584 described by prisms or needles with a high specific surface area. The formation of AFt on the surface 585 of cement grain results in a strong friction force between interparticle. The AFt crystal outside the 586 grains interlace with each other to establish an interspace reticulate structure in fresh paste. The 587 gypsum is yielded in the space among cement particles. The morphology of gypsum is rod-like and 588 the size of gypsum is an order of magnitude bigger than needle-like AFt [19]. The network formed by 589 gypsum provided a rigid tie for cement grain, which makes the structure of blend stronger.

591 Therefore, the structural build-up of OPC-CSA-C $\bar{S}$ ternary blends originated from the rigid links of CSH and AFt and the gypsum network, as well as colloidal surface interaction.

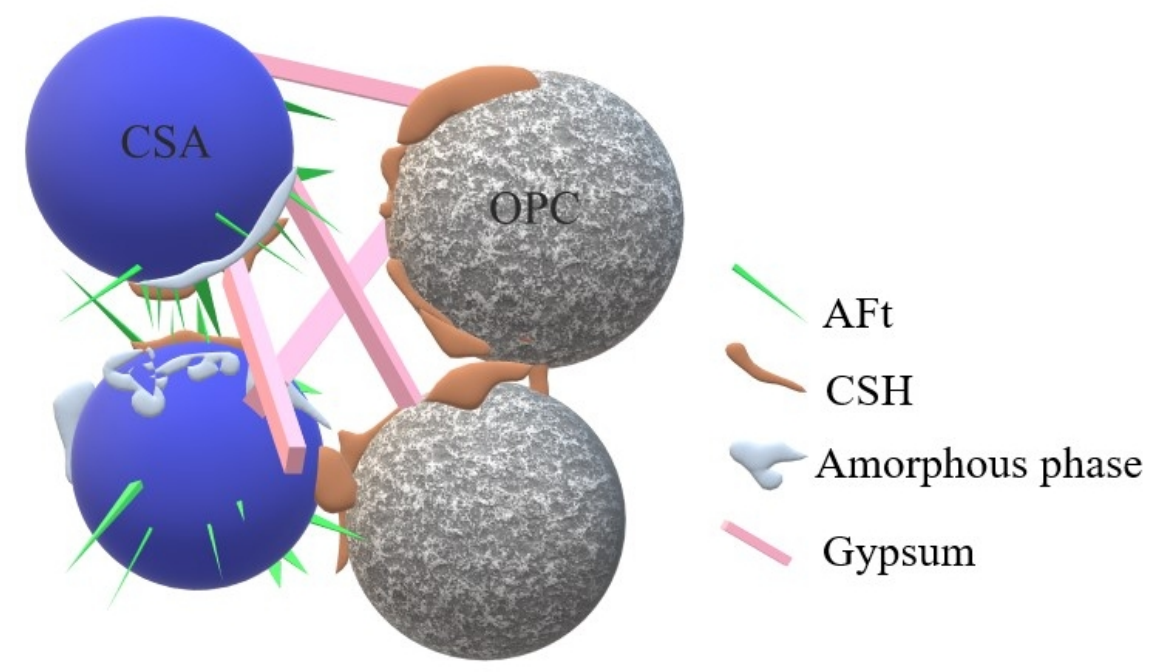

Fig. 12. Schematic drawing of the hydrates covered on the surface of cement particles and the network(s) of interacting cement particles in OPC-CSA- $\bar{S}$ ternary system during the dormant period. 
and the structural build-up rate (section 3.3), it suggests that the role of CSA and CS on accelerating structural build-up is due to their positive effect on the hydration kinetics of main hydrates. The nucleation and growth kinetics of hydrates calculated from calorimetry data, shown in Table 9, is used to describe the relationship between hydration and structural build-up rate and it is a good evidence to explain the impact of the $\mathrm{C} \overline{\mathrm{S}}$ and CSA.

600

601 Fig. 13 plots the structural build-up rate of blends $A_{\text {thix }}$ value with the growth kinetics of hydrates $\mathrm{K}_{\mathrm{G}}$ value. As the plot shows, the $A_{\text {thix }}$ value increases with $K_{G}$ value, and the curve agrees with the exponential relation. It means that the rate of filling the pore space between particles in unit volume of paste plays an important role on the structural build-up rate. And, the increase of CSA and CS accelerate the filling rate of hydrate in the pore of initial structure, thus they speed up the structural build-up rate of blends.

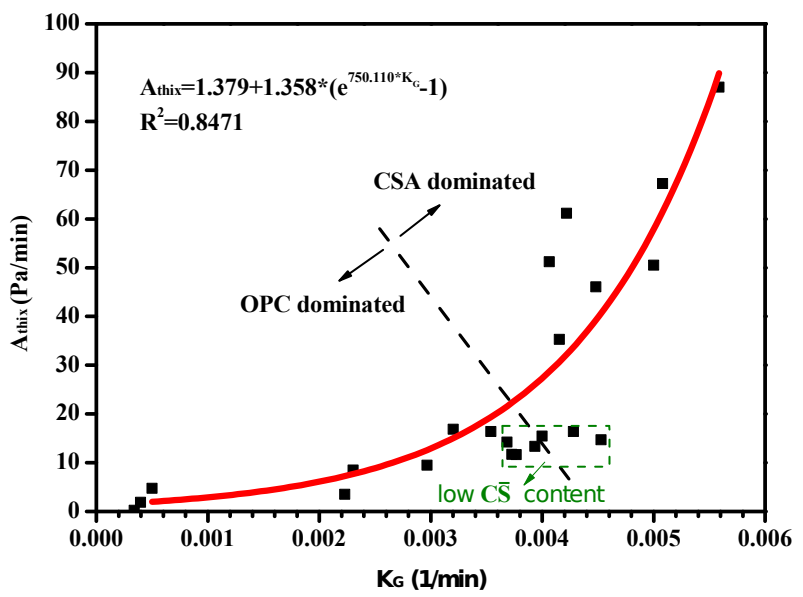

Fig. 13. The relationship between the growth kinetics of hydrates $K_{G}$ and the structural build-up rate $A_{\text {thix }}$ of ternary blends

\section{Conclusions}

609 Based on the aforementioned results and discussion, the following conclusions can be drawn: 

Herschel-Bulkley model and modified Bingham model is suitable for calculating the rheological 612 parameters of fresh ternary blends.

614 2. The rheological parameters of OPC-CSA-C $\bar{S}$ blends depend on OPC/CSA ratio and the content of $615 \mathrm{C} \overline{\mathrm{S}}$. The high content of CSA causes a higher dynamic yield stress and apparent viscosity. The 616 increase of $\mathrm{C} \bar{S}$ favors the flowability of blends by reducing the dynamic yield stress, although it 617 leads to a higher apparent viscosity. $C \bar{S}$ in a ternary system improves the extent of shear thinning. 618 Besides, the higher amount of CSA and the high proportion of $\mathrm{C} \bar{S}$ in system collectively 619 accelerates the structural build-up of blends. Thus, the appropriate increase of $\bar{C} \bar{S}$ not only benefits 620 flowability under casting, but also helps re-structuration at rest.

3. CSA and $\bar{C} \bar{S}$ have different effects on initial rheology, while they both make positive effects on the structural build-up of blends. This may stem from the difference between their effects on electro-kinetics and hydration kinetics.

4. The initial rheology of ternary blends depends on the electro-kinetics. The dynamic yield stress of the blend relates closely with zeta potential. The increase of CSA reduces the zeta potential of blends. It results in a weak repulsive electrostatic force and a correspondingly stronger attraction 631

5. The structural build-up of blend attributes to the formation of main hydrates, including $\mathrm{CSH}, \mathrm{AFt}$ 
and gypsum, and their nucleation and growth kinetics. The network established by crystal with various scales and rigid bridges between particles makes a stronger structure of ternary blends. The higher growth kinetics of those hydrates is, the faster structuration rate is. The CSA and anhydrate enlarge the $\mathrm{K}_{\mathrm{G}}$ value of hydrates, which accelerates the filling rate of hydrates in the spaces of the structure. It is responsible for their positive effect on structural build-up. Besides, the delaying action of $\mathrm{C} \bar{S}$ on hydration process explains its desirable influence on initial flowability.

\section{Acknowledgments}

Financial supports by National Key R\&D Program of China (contract No. 2017YFB0310100) and National Natural Science Foundation of China (contract No. 51778629) are greatly appreciated.

\section{References}

[1] P. Chaunsali, P. Mondal, J. Bullard, Influence of Calcium Sulfphoaluminate (CSA) Cement Content on Expansion and Hydration Behavior of Various Ordinary Portland Cement-CSA Blends, J. Am. Ceram. Soc., 98(2015):1-8.

[2] I. Mehdipour, K. Khayat, Enhancing the performance of calcium sulfphoaluminate blended cements with shrinkage reducing admixture or lightweight sand, Cem Concr Comp. 87(2018), 29-43.

[3] M. Polivka, C. Willson, Properties of Shrinkage-Compensating Concretes, ACI Publication No. SP-38. 227-37, 1973

[4] A. Klein and C. Troxell, Studies of Calcium Sulfphoaluminate Admixtures or Expansive Cements, Am. Soc. Test. Mater., 58(1958) 986-1008. 
[5] K. Nakagawa, Y. Watanabe, I. Mino, T. Kitsuta, Adoption of Electrofused Calcium Sulphoaluminate Clinker for Ultra-high Strength Concrete, Proceedings of the 6th International Congress on the Chemistry of Cement (ICCC), Supplementary Paper, Section 3, URSS, Moscow, 1974.

[6] M. Cohen. Theories of expansion in sulfphoaluminate - type expansive cements: schools of thought. Cem Concr Res, 13(1983) 809-18.

[7] M. Ish-Shalom, A. Bentur, Properties of type K expansive cement of pure components I. Hydration of unrestrained paste of expansive component results. Cem Concr Res, 4(1974) 51932.

[8] A. Bentur, M. Ish-Shalom, Properties of type K expensive cement of pure components II. Proposed mechanism of ettringite formation and expansion in unrestrained paste of pure expansive component. Cem Concr Res. 4(1974) 709-21.

[9] M. Ish-Shalom, A. Bentur, Properties of type K expansive cement of pure components III. Hydration of pure expansive component under varying restraining conditions. Cem Concr Res, $5(1975)$ 139-52.

[10] I. Janotka, U. Krajči, An experimental study on the upgrade of sulfphoaluminate-belite cement systems by blending with Portland cement, Adv. Cem. Res. 11(1999), 35-41.

[11] I. Janotka, L. Krajči, A. Ray, S.C. Mojumdar, The hydration phase and pore structure formation in the blends of sulfphoaluminate-belite cement with Portland cement, Cem Concr Res, 33 (2003) $489-497$

[12] R. Trauchessec, J. Mechling, A. Lecomte, A. Roux, B. Le Rolland, Hydration of ordinary Portland cement and calcium sulfphoaluminate cement blends, Cem Concr Comp. 56(2015), 106- 
114.

[13] P. Laure, W. Frank, L. Barbara, The ternary system Portland cement-calcium sulphoaluminate clinker-anhydrite: Hydration mechanism and mortar properties, Cem Concr Comp. $32(2010), 497-507$.

[14] L. Pelletierchaignat, F. Winnefeld,B. Lothenbach, Influence of the calcium sulphate source on the hydration mechanism of Portland cement-calcium sulphoaluminate clinker-calcium sulphate binders, Cem Concr Comp. 33(2011) 551-561.

[15] D. Gastaldi, F. Canonico, L. Capelli, M. Bianchi, M. Pace, A. Telesca, Hydraulic behaviour of calcium sulfphoaluminate cement alone and in mixture with Portland cement. In: Proc. 13th int. congr. chem. cem., Madrid, Spain; 2011,412.

[16] K. Kano, Quality control system and predication of strength from phase composition of very high early strength cement, Cem Sci Concr Technol. 52(1998), 16-21.

[17] J. Bullard, H. Jennings, R. Livingston, Mechanisms of cement hydration, Cem. Concr. Res., 41(2011):1208-1223.

[18] P. Chaunsali, P. Mondal, Physico-chemical interaction between mineral admixtures and OPCcalcium sulfphoaluminate (CSA) cements and its influence on early-age expansion, Cem. Concr. Res., 80 (2016)10-20.

[19] H. Taylor. Cement chemistry. London: Thomas Telford Publishing; 1997.

[20] R. Myers, G. Geng, J. Li, E. Rodríguez, J. Ha, P. Kidkhunthod, G. Sposito, L.N. Lammers, A.P. Kirchheim, P.J.M. Monteiro, Role of adsorption phenomena in cubic tricalcium aluminate dissolution, Langmuir., 33 (2017) 45-55

[21] J. Skalny, M.E. Tadros, Retardation of Tricalcium aluminate hydration by sulfates, J. Am. Ceram. 
[22] F. Winnefeld , S. Barlag, Calorimetric and thermogravimetric study on the influence of calcium sulfate on the hydration of ye'elimite, J. Therm. Anal. Calorim., 101(2010) 949-957.

[23] F. Glasser, Advances in sulfphoaluminate cements. In: Proceedings $5^{\text {th }}$ international symposium on the cement and concrete, vol. 1; 2002. p. 14-24

[24] D. Jiao, C. Shi, Y. Qiang, Effect of constituents on rheological properties of fresh concrete-A review, Cem Concr Comp., 83(2017) 146-159.

[25] D. Marchon, S. Kawashima, H. Bessaies-Bey, S. Mantellato and S. Ng, Hydration and rheology control of concrete for digital fabrication: Potential admixtures and cement chemistry, Cem. Concr. Res. 112 (2018), 96-110.

[26] L. Reiter, T. Wangler, N. Roussel and R. J. Flatt, The role of early age structural build-up in digital fabrication with concrete, Cem. Concr. Res., 112 (2018), 86-95.

[27] D. Asprone, C. Menna, F. P. Bos, T. A. M. Salet, J. Mata-Falcón and W. Kaufmann, Rethinking reinforcement for digital fabrication with concrete, Cem. Concr. Res., 112 (2018), 111-121.

[28] N. Roussel, Rheological requirements for printable concretes, Cem. Concr. Res., 112 (2018), 76-85.

[29] N. Khalil, G. Aouad, Use of calcium sulfphoaluminate cements for setting control of 3Dprinting mortars, Constr. Build. Mater., 157(2017) 382-391.

[30] R. Kwasny-Echterhagen, L. Amathieu, F. Estienne, Calcium Aluminate Cement: A Polyvalent Blender for Various Applications in the Building Industry, Proceedings of the International Conference on Dry Mixes, St. Peterssburg., 2003.

[31] J. Mork, O. Gjørv, Effect of gypsum-hemihydrate ratio in cement on rheological properties of 
fresh concrete, ACI Mater. J. 94 (2) (1997) 142 146.

[32] J. Dils, V. Boel, G. De Schutter, Influence of cement type and mixing pressure on air content, rheology and mechanical properties of UHPC, Constr. Build. Mater. 41 (2013) 455 463

[33] M. García-Maté, I. Santacruz, Rheological and hydration characterization of calcium sulfphoaluminate cement pastes, Cem Concr Comp., 34(2012) 684-691.

[34] A. Mostafa, A. Yahia, Physico-chemical kinetics of structural build-up of neat cement-based suspensions, Cem. Concr. Res. 97 (2017) 11-27.

[35] N. Roussel, G. Ovarlez, S. Garrault, C. Brumaud, The origins of thixotropy of fresh cement pastes, Cem. Concr. Res., 42 (2012) 148-157.

[36] Q. Yuan, X.Lu, K.H Khayat., D. Feys, C. Shi, Small amplitude oscillatory shear technique to evaluate structural build-up of cement paste, Mater. Struct. 50 (2017) 1-12.

[37] Q. Yuan, D. Zhou, K.H Khayat., D. Feys, C. Shi,On the measurement of evolution of structural build-up of cement paste with time by static yield stress test vs. small amplitude oscillatory shear test, Cem. Concr. Res., (2017), 183-189.

[38] A. Perrot, A., D. Rangeard, A. Pierre, Structural built-up of cement-based materials used for 3Dprinting extrusion techniques, Mater. Struct. 49 (2016), 1213-1220

[39] R. Wolfs, F. Bos, T. Salet, Early age mechanical behaviour of 3D printed concrete: Numerical modelling and experimental testing. Cem. Concr. Res., 106 (2018), 103-116.

[40] T. Wangler, E. Lloret, L. Reiter, N. Hack, F. Gramazio, M. Kohler, R. Flatt, Digital concrete: opportunities and challenges. RILEM Technol. Lett., 1(2016), 67-75.

[41] J. Assaad, K. Khayat, Effect of viscosity-enhancing admixtures on formwork pressure and thixotropy of self-consolidating concrete, ACI Mater. J., 103 (2006) 280-287. 
[42] K. Khayat, J. Assaad, Effect of w/cm and high-range water-reducing admixture on formwork pressure and thixotropy of self-consolidating concrete, ACI Mater. J., 103 (2006) 186-193.

[43] J. Assaad, K. Khayat, J. Daczko, Evaluation of static stability of self-consolidating concrete, ACI Mater. J., 101 (2004) 168 - 176.

[44] M. Rahman, M. Baluch, M. Malik, Thixotropic behavior of self-compacting concrete with different mineral admixtures, Constr. Build. Mater., 50(2014), 710-717.

[45] R. Ahari, T. Erdem, K. Ramyar, Thixotropy and structural breakdown properties of selfconsolidating concrete containing various supplementary cementitious materials, Cem. Concr. Comp., 59(2015), 26-37.

[46] A. Mostafa, A. Yahia, New approach to assess build-up of cement-based suspensions, Cem. Concr. Res., 85 (2016) 174-182.

[47] Q. Yuan, D. Zhou, Effect of mineral admixtures on the structural build-up of cement paste, Constr. Build. Mater., 160(2018)117-126.

[48] N. Tregger, M. Pakula, S. Shah, Influence of clays on the rheology of cement pastes, Cem. Concr. Res., 40 (2010) 384-391

[49] S. Kawashima, M. Chaouche, D. Corr, Rate of thixotropic rebuilding of cement pastes modified with highly purified attapulgite clays, Cem. Concr. Res., 53 (2013) 112-118.

[50] R. Ferron, A. Gregori, Z. Sun, S. Shah, Rheological method to evaluate structural buildup in selfconsolidating concrete cement past, ACI Mater. J. 104(2007) 242-50.

[51] Z. Quanji, G. Lomboy, K. Wang, Influence of nano-sized highly purified magnesium alumino silicate clay on thixotropic behavior of fresh cement pastes, Constr. Build. Mater., 69 (2014) 295300. 
[52] Y. Qian and G. De Schutter, Enhancing thixotropy of fresh cement pastes with nanoclay in presence of polycarboxylate ether superplasticizer (PCE), Cem. Concr. Res., 111 (2018), 15-22.

[53] K. Khayal, J. Assaad, Use of Thixotropy-Enhancing agent to reduce formwork pressure exerted by Self-Consolidating concrete, ACI Mater. J., 105 (2008) pp. 88.

[54] ] A. Perrot, A. Pierre, S. Vitaloni and V. Picandet, Prediction of lateral form pressure exerted by concrete at low casting rates, Mater. Struct. 48 (2015), 2315-2322.

[55] Electro acoustics tutorial and zeta probe operators manual, Colloidal Dynamics; 2004

[56] J. Cahn, The kinetics of grain boundary nucleated reactions, Acta Metall. 4 (1956) 449-459.

[57] G. Scherer, J. Zhang, J. Thomas, Nucleation and growth models for hydration of cement, Cem. Concr. Res., 42 (2012) 982-993.

[58] H. Zhou, J. Liu, hydration kinetics process of low alkalinity sulphoaluminate cement and its thermodynamical properties, Procedia Engineering, 27(2012) 323-331.

[59] G. Artioli, J. Bullard, Cement hydration: the role of adsorption and crystal growth, Cryst. Res. Technol. 48 (10) (2013) 903-918.

[60] P. Brown, L. Liberman, G. Frohnsdorff, Kinetics of the early hydration of Tricalcium aluminate in solutions containing calcium sulfate, J. Am. Ceram. Soc. 67 (1984) 793-795.

[61] K. Scrivener, P. Juilland, P. Monteiro, Advances in understanding hydration of Portland cement, Keynote Pap 14th Int Congr Chem Cem ICCC 2015, 78, Part A, 2015, pp. 38-56.

[62] L. Buffo-Lacarrière, A. Sellier, G. Escadeillas, A. Turatsinze, Multiphasic finite element modeling of concrete hydration, Cem. Concr. Res., 37 (2007) 131-138.

[63] J. Wang, Hydration mechanism of cements based on low- $\mathrm{CO}_{2}$ clinkers containing belite, ye'elimite and calcium alumino-ferrite. PhD Thesis University of Lille, France, 2010. 
[64] F. De Larrard, C. Ferraris, T. Sedran, Fresh concrete: a Herschel-Bulkley material, Mater. Struct. 31 (7) (1998) 494 498.

[65] A. Otsuki, Coupling colloidal forces with yield stress of charged inorganic particle suspension: A review, Electrophoredis, 39(2018) 690-701.

[66] J. Zhou, K. Zheng, Chemical effect of nano-alumina on early-age hydration of Portland cement, Cem. Concr. Res., 116(2019) 159-167.

[67] P. Banfill, X. Yongmot, P. Domonet, Relationship between the rheology of unvibrated fresh concrete and its flow under vibration in a vertical pipe apparatus, Mag. Concr. Res. 51 (3) (1999) 181-190.

[68] N. Roussel, P. Coussot, "Fifty-cent rheometer" for yield stress measurements: from slump to spreading flow, J. Rheology. 49 (2005) 705-718.

[69] N. Pashias, D. Boger, J. Summers, D. Glenister, A fifty cent rheometer for yield stress measurement, J. Rheology, 40 (1996) 1179-1189

[70] A. Pierre, C. Lanos, P. Estelle, Extension of spread-slump formulae for yield stress evaluation, Appl. Rheol. 23 (2013) 63849.

[71] R. Flatt, P. Bowen, Yield stress of multimodal powder suspensions: an extension of the YODEL (yield stress model), J. am. Ceram. Soc. 90 (2007) 1038-1044.

[72] R. Flatt, P. Bowen, Yodel: a yield stress model for suspensions, J. am. Ceram. Soc., 89 (2006) $1244-1256$

[73] P. Kapur, P. Scales, D. Boger, Yield stress of suspensions loaded with size distributed particles, Aiche J., 43(1997):1171-1179.

[74] P. Scales, S. Johnson, T. Healy, Shear yield stress of partially flocculated colloidal suspensions, 
Aiche J., 44(1998) 538-544.

811 [75] S. Johnson, G. Franks, P. Scales, Surface chemistry-rheology relationships in concentrated mineral suspensions, Int. J. Miner Process., 58(2000):267-304.

813 [76] N. Roussel, A thixotropy model for fresh fluid concretes: theory, validation and applications, Cem. $814 \quad$ Concr. Res., 36 (2006) 1797-1806.

815 [77] J. Peng, J. Qu, J. Zhang J, Adsorption characteristics of water-reducing agents on gypsum surface 816 Res., 32(2002) 1725-1728. with alkaline cations, J. Colloid. Interface Sci., 244(2001), 58-65. 